Article

\title{
Synthesis and Structure-Activity Relationships of Imidazole-Coumarin Conjugates against Hepatitis C Virus
}

\author{
Shwu-Chen Tsay ${ }^{1,2, *}$, Shu-Yu Lin ${ }^{1}$, Wen-Chieh Huang ${ }^{1}$, Ming-Hua Hsu ${ }^{1}$, Kuo Chu Hwang ${ }^{1}$, \\ Chun-Cheng Lin ${ }^{1}$, Jia-Cherng Horng ${ }^{1}$, I-Chia Chen ${ }^{1}$, Jih Ru Hwu ${ }^{1,2, *}$, Fa-Kuen Shieh ${ }^{2}$, \\ Pieter Leyssen ${ }^{3}$ and Johan Neyts ${ }^{3, *}$ \\ 1 Department of Chemistry \& Frontier Research Center on Fundamental and Applied Sciences of Matters, \\ National Tsing Hua University, Hsinchu 30013, Taiwan; kchlsu@mail2000.com.tw (S.-Y.L.); \\ jordanback2001@yahoo.com.tw (W.-C.H.); minghua.hsu@gmail.com (M.-H.H.); \\ kchwang@mx.nthu.edu.tw (K.C.H.); cclin66@mx.nthu.edu.tw (C.-C.L.); jchorng@mx.nthu.edu.tw (J.-C.H.); \\ icchen@mx.nthu.edu.tw (I.-C.H.) \\ 2 Department of Chemistry, National Central University, Jhongli District, Taoyuan City 32001, Taiwan; \\ fshieh@ncu.edu.tw \\ 3 Rega Institute for Medical Research, Katholieke Universiteit Leuven, Minderbroedersstraat 10, \\ Leuven B-3000, Belgium; pieter.leyssen@rega.kuleuven.be \\ * Correspondence: tsay.susan@gmail.com (S.-C.T.); jrhwu@mx.nthu.edu.tw (J.R.H.); \\ johan.neyts@rega.kuleuven.be (J.N.); Tel.: +886-3-572-5813 (J.R.H.); Fax: +886-3-572-1594 (J.R.H.)
}

Academic Editor: Derek J. McPhee

Received: 21 January 2016 ; Accepted: 4 February 2016 ; Published: 18 February 2016

\begin{abstract}
A series of new conjugated compounds with a $-\mathrm{SCH}_{2}-$ linkage were synthesized by chemical methods from imidazole and coumarin derivatives. The experimental results indicate that of the twenty newly synthesized imidazole-coumarin conjugates, three of them exhibited appealing $\mathrm{EC}_{50}$ values $(5.1-8.4 \mu \mathrm{M})$ and selective indices $>20$ against hepatitis $\mathrm{C}$ virus. Their potency and selectivity were increased substantially by modification of their structure with two factors: imidazole nucleus with a hydrogen atom at the $\mathrm{N}(1)$ position and coumarin nucleus with a substituent, such as $\mathrm{Cl}, \mathrm{F}, \mathrm{Br}, \mathrm{Me}$, and $\mathrm{OMe}$. These guidelines provide valuable information for further development of conjugated compounds as anti-viral agents.
\end{abstract}

Keywords: imidazole; nitrogen heterocycles; coumarin; hepatitis C virus; structure-activity relationships

\section{Introduction}

Hepatitis C virus (HCV) infection afflicts $~ 150$ million people worldwide ( $3 \%$ of the global population), with approximately 3-4 million new cases occurring annually [1]. HCV generally causes both mild and acute liver disease, possibly leading to cirrhosis, hepatocellular carcinoma, and liver failure. The traditional therapeutic treatment involves administering interferon $\alpha-2$ or its PEGylated form, either alone or in combination with ribavirin [2,3]. In 2011, boceprevir and telaprevir were approved for the treatment of chronic hepatitis $C$ genotype 1 infection in combination with peg-interferon $\alpha$ and ribavirin. The recommended treatment regimens have significantly increased the overall cure rates $[4,5]$. The above therapeutic treatments, however, still have substantial adverse effects [6]. During the past two years, the U.S. Food and Drug Administration has approved Harvoni ${ }^{\mathrm{TM}}$ (ledipasvir/sofosbuvir), simeprevir, sofosbuvir, and Viekira Pak ${ }^{\mathrm{TM}}$ (ombitasvir/paritaprevir/ritonavir tablet; dasabuvir tablet). Harvoni ${ }^{\mathrm{TM}}$ and Viekira Pak ${ }^{\mathrm{TM}}$ are combination pills in which each of the 
active ingredients therein has a distinct mechanism of action (MOA) [7,8]. As new generation drugs for the treatment of HCV infections, the recommended 12- or 24-week courses of therapy of both are highly expensive [9]. Thus, pharmaceutical companies are still seeking chemical entities with safer and lower price than the existing drugs to combat the HCV disease. Our recent works introduced a series of coumarin-containing conjugated compounds as new anti-HCV agents, including benzimidazole-, heterobicycle-, and (ribosyl)purine-coumarin conjugates [10-14]. The aim of this work was to synthesize new compounds with a scaffold containing a coumarin moiety that is conjugated with an imidazole moiety or its derivatives, including (1-ribofuranosyl)imidazole, inosine, and guanosine. Their anti-HCV activity is to be explored and their structure-activity is to be deduced.

Coumarins belong to an important family of compounds with various pharmacological functions $[15,16]$. Despite the development of their derivatives as HCV NS3 4A protease inhibitors and NS5B polymerase inhibitors [15,17], the flat and shallow substrate-binding groove of proteases inhibits their potency and selectivity $[18,19]$.

Imidazole derivatives and imidazole-2-thiones represent a class of compounds with important pharmacological properties, including anti-bacterial [20], anti-inflammatory [21], anti-cancer [22], and anti-viral activities $[23,24]$. In the histidine moieties of enzymes, the imidazole ring functions as a proton donor or acceptor or both in enzymic reactions in the charge-relay system when it is in a free base form [25]. Therefore, many well-known biocatalysts possess this moiety. Several investigations have elucidated the $N$-alkylation of imidazole compounds, which alter the pharmacological actions and pharmacokinetics [26,27].

In 2010, Zai and co-workers [28] reported that inosine alters gene expression and axonal projections in neurons contralateral to a cortical infarct. Additionally, it exerts a broad range of anti-inflammatory effects in a murine model of acute lung injury, as found by Liaud et al. [29]. Inosine is also the major component of the drug isoprinosine for the treatment of chronic hepatitis B. This drug inhibits replication of many RNA and DNA viruses in vivo and in vitro [30]. It also exerts an immunostimulatory effect by enhancing T-cell function and macrophage activity [31]. Containing inosine as a major component, the drug Isoprinosine unfortunately exhibits several side effects [32]. Those effects include dyspepsia, hypersensitivity reactions, and severe drug reactions with ribavirin that may result in a drop in the white blood cell count of patients.

Giuliani and co-workers [33] recognized protective activity of guanosine in an in vitro model of Parkinson's disease. Very recently, Gosselin et al. [34] reported a 2'-C-methyl branched guanosine pro-nucleotide as a potent liver-targeted HCV polymerase inhibitor. Schaefer-Korting et al. [35] found that a guanosine-analog phosphonate can improve topical non-melanoma skin cancer treatment.

This work extends the range of available benzimidazole-coumarin conjugates by replacement of the benzimidazole moiety therein with an imidazole moiety or its derivatives (i.e., inosine and guanosine). An attempt is also made to understand how they influence the anti-HCV activity of the conjugated compounds by use of three structural relatives, namely $\mathrm{N}-\mathrm{H}, \mathrm{N}$-methyl, and $\mathrm{N}$-ribofuranosyl imidazoles. Additionally, various substituents (i.e., $\mathrm{F}, \mathrm{Cl}, \mathrm{Br}, \mathrm{Me}$, and $\mathrm{OMe}$ ) are attached to the coumarin moiety. In total, 20 imidazole-coumarin conjugated compounds with the common skeleton shown in Figure 1 below were synthesized and their structure-activity relationships derived.

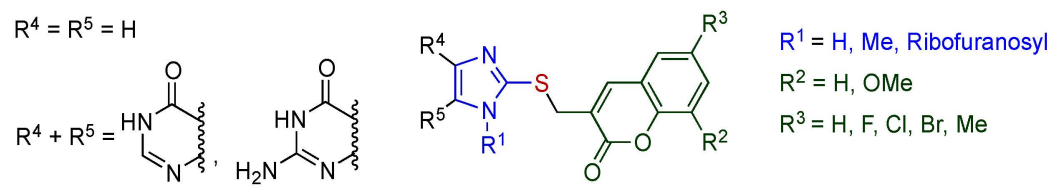

Figure 1. General structure of targed imidazole-coumarin conjugates. 


\section{Results and Discussion}

\subsection{Chemistry}

To investigate the effects of different moieties or functional groups attached to the core, our research group synthesized four series of imidazole-coumarin conjugated compounds. The corresponding synthetic procedures are described as follows.

\subsubsection{Synthesis of Imidazole-Coumarin Conjugates}

Conjugates with a coumarin moiety attached at the C(2)-position of the imidazole group via a thiomethylene joint were synthesized. Correspondingly, $1 H$-imidazole-2-thiol (1a) was coupled with various 3-(chloromethyl)coumarins 2 in the presence of aqueous ammonia and acetonitrile. Conjugates 3a-e with different substituents (e.g., F, Cl, Br, and $\mathrm{OMe}$ ) were obtained in $65 \%-86 \%$ yields. Furthermore, their methyl analogs (i.e., $3 \mathbf{f}$ and $3 \mathbf{g}$ ) were prepared by alkylation of 1-methylimidazole-2-thiol (1) $)$ with coumarins $\mathbf{2 a}$ and $\mathbf{2 c}$, respectively. Under these alkaline conditions, the $\mathrm{NH}$ group of $\mathbf{1}$ did not compete with the $\mathrm{C}(2)$-thiol group for nucleophilic attack of the coumarin substrates [12] (Scheme 1).

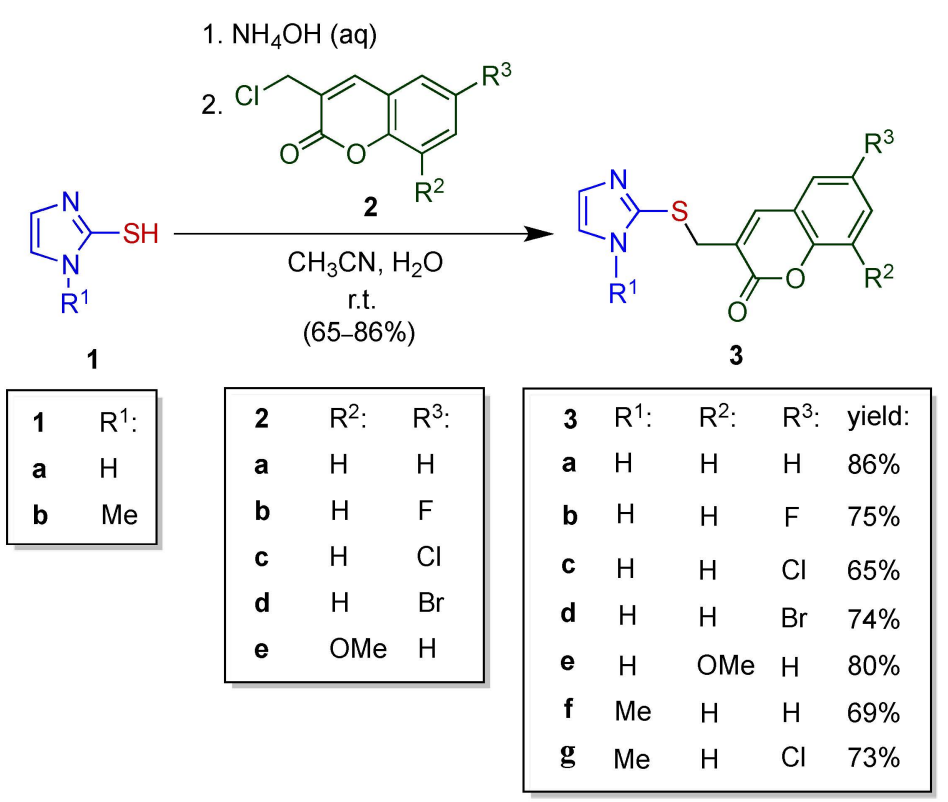

Scheme 1. Synthesis of imidazole-coumarin conjugates.

\subsubsection{Synthesis of (1-Ribofuranosyl)imidazole-Coumarin Conjugates}

Nucleoside derivatives are promising candidates for anti-viral drugs [36,37], which explains our intention to prepare (1-ribofuranosyl)imidazole-coumarin conjugates for an anti-viral activity assay. First, silylation of $1 \mathrm{H}$-imidazole-2-thiol (1a) with $\mathrm{N}$,O-bis(trimethylsilyl)acetamide (BTSA) [38] gave the intermediates, which were then coupled with 1,2,3,5-tetra- $O$-acetyl- $\beta$-D-ribofuranose (4) in the presence of $\mathrm{Me}_{3} \mathrm{SiOTf}$ and acetonitrile at $80^{\circ} \mathrm{C}$. Subsequent removal of the three acetyl groups in 5 with $\mathrm{K}_{2} \mathrm{CO}_{3}$ in methanol provided the resultant thiol 6. Its coupling [39] with coumarins 2 produced (1-ribofuranosyl)imidazole-coumarin conjugates 7 in good yields (72\%-84\%) (Scheme 2). 


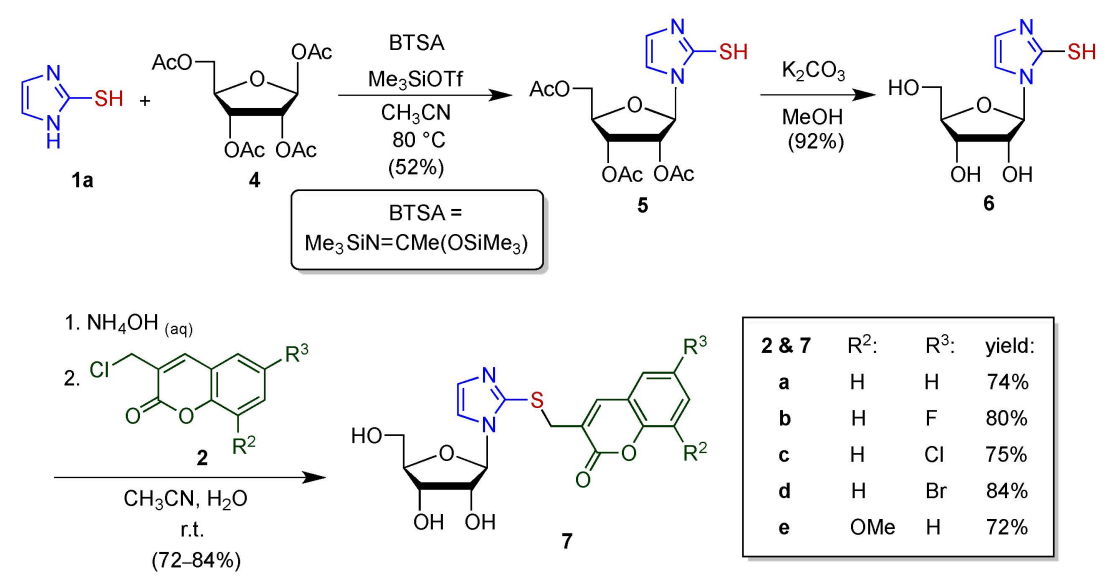

Scheme 2. Synthesis of (1-ribofuranosyl)imidazole-coumarin conjugates.

\subsubsection{Synthesis of Inosine- and Guanosine-Coumarin Conjugates}

We found that the desired $S_{N} 2$ reactions occurred at the thiol group of compounds 8 [40] and 10 [41] with the allylic position of 3-(chloromethyl)coumarins 2 to give the desired conjugated products 9 and 11, respectively. The unwanted Michael addition did not occur at the $\alpha, \beta$-unsaturated lactone moiety of coumarins 2 . The key factors for success involved the use of $35 \%$ aqueous ammonia and acetonitrile as the media at room temperature. Accordingly, yields of $70 \%-83 \%$ for inosine-coumarins $\mathbf{9}$ and $74 \%-89 \%$ for guanosine-coumarins $\mathbf{1 1}$ were obtained (Scheme 3 ).

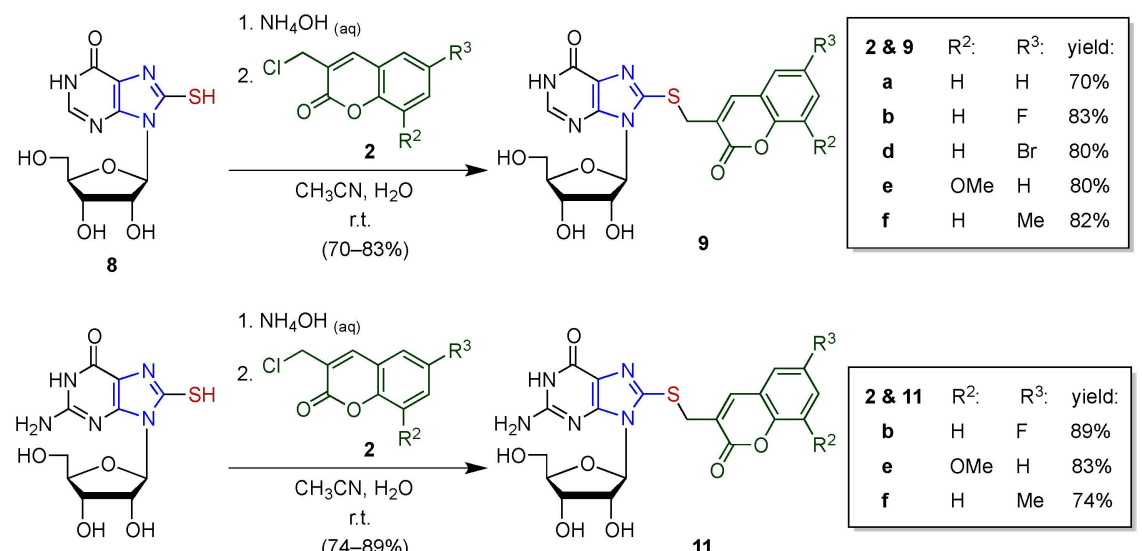

10

$$
(74-89 \%)
$$

Scheme 3. Synthesis of inosine- and guanosine-coumarin conjugates.

\subsubsection{Identification of the Structures of New Conjugated Compounds}

The structures of all newly synthesized compounds were confirmed on the basis of their spectroscopic characteristics. For instance, the IR spectrum of conjugates $7 \mathbf{a}$ displayed a strong absorption band at $1698 \mathrm{~cm}^{-1}$, which was contributed to the carbonyl stretching vibration of the coumarin moiety [42]. Its ${ }^{13} \mathrm{C}-\mathrm{NMR}$ spectrum had resonances at 34.27 and $151.94 \mathrm{ppm}$ for the $\mathrm{SCH}_{2}$ carbon and the $-\mathrm{N}=\mathrm{C}(-\mathrm{N})(-\mathrm{S})$ carbons, respectively. Furthermore, a doublet with $J=7.2 \mathrm{~Hz}$ occurred at $5.67 \mathrm{ppm}$ for the glycosidic proton [43] in its ${ }^{1} \mathrm{H}-\mathrm{NMR}$ spectrum. Nevertheless, it was beyond our expection that the two characteristic singlets, instead of doublets, occurred at 7.49 and $6.99 \mathrm{ppm}$ for the protons in the imidazole nucleus. Our data are in consistent with those of $N$-( $\beta$-D-ribofuranosyl)imidazole, the parent compound of $7 \mathbf{a}$, as reported by Mourabit and co-workers [44]. 
In addition, a doublet with $J=6.4 \mathrm{~Hz}$ at $5.76 \mathrm{ppm}$ in the ${ }^{1} \mathrm{H}-\mathrm{NMR}$ spectrum was assigned as the anomeric hydrogen of compound 9a. They also exhibited two characteristic doublets at 4.39 and 4.34 ppm with $J=14.2 \mathrm{~Hz}$ for the two $\mathrm{SCH}_{2}$ hydrogens and a singlet at 8.06 ppm for the $\mathrm{NH}-\mathrm{CH}=\mathrm{N}$ proton in inosine moiety. In its ${ }^{13} \mathrm{C}-\mathrm{NMR}$ spectrum, resonance occurred at $32.04 \mathrm{ppm}$ for the $\mathrm{SCH}_{2}$ carbon.

\subsection{Pharmacology}

\section{Anti-HCV Activity}

The antiviral activity of conjugated compounds $\mathbf{3 a}-\mathbf{g}, \mathbf{7} \mathbf{a}-\mathbf{e}, \mathbf{9 a}, \mathbf{b}, \mathbf{d}-\mathbf{f}$, and $\mathbf{1 1} \mathbf{b}, \mathbf{e}, \mathbf{f}$ in the HCV genotype $1 \mathrm{~b}$ subgenomic Huh 5-2 replicon system [45] was evaluated according to established procedures [46]. On the basis of the dose-response curves that were obtained, the concentration of a compound that inhibited virus replication by 50\% (i.e., $\mathrm{EC}_{50}$ ) and the concentration of compound that reduced host cell metabolism by $50 \%$ (i.e., $\mathrm{CC}_{50}$ ) were obtained. These values subsequently allowed us to calculate the selectivity index (i.e., $\mathrm{SI}=\mathrm{CC}_{50} / \mathrm{EC}_{50}$ ), which is a measure for the therapeutic window of the compound in an assay system. Compounds were only considered as selective inhibitors in the replicon assay when virus RNA replication was significantly inhibited $(>70 \%)$ at concentrations not adversely affecting the host cell metabolism. The observed antiviral effect of other compounds was most likely related mainly to the pleiotropic or aspecific effect on the host cell.

Of the 20 newly synthesized conjugates, five (i.e., 3b-f) exhibited appealing antiviral activity with $\mathrm{EC}_{50}$ values of 5.1-9.7 $\mu \mathrm{M}$ in the HCV 1b Huh 5-2 replicon system (Table 1). Three conjugates $\mathbf{3 b}, \mathbf{3 d}$, and 3e displayed a significant window of selectivity with SI of 12-21.

Table 1. Anti-metabolic and antiviral effect of conjugated compounds on HCV 1b subgenomic replicon replication in Huh 5-2 cells.

\begin{tabular}{|c|c|c|c|}
\hline Compound ${ }^{a}$ & $\mathrm{CC}_{50}{ }^{\mathrm{b}}(\mu \mathrm{M})$ & $\mathrm{EC}_{50}{ }^{\mathrm{c}}(\mu \mathrm{M})$ & SI $^{d}$ \\
\hline $3 a$ & 122 & 30 & 4.1 \\
\hline $3 b$ & 83 & 7.2 & 12 \\
\hline $3 c$ & 85 & 9.7 & 8.8 \\
\hline $3 d$ & 75 & 5.1 & 15 \\
\hline $3 e$ & 173 & 8.4 & 21 \\
\hline $3 f$ & 49 & 6.7 & 7.3 \\
\hline $3 g$ & 75 & 15 & 5.1 \\
\hline $7 a$ & 128 & 59 & 2.2 \\
\hline $7 \mathrm{~b}$ & 122 & 26 & 4.7 \\
\hline $7 c$ & 85 & 14 & 6.3 \\
\hline $7 d$ & 107 & 19 & 5.7 \\
\hline $7 e$ & 119 & 34 & 3.5 \\
\hline $9 a$ & 109 & 61 & 1.8 \\
\hline $9 b$ & 105 & 73 & 1.4 \\
\hline $9 d$ & 93 & 70 & 1.3 \\
\hline $9 e$ & 102 & 102 & 1.0 \\
\hline $9 f$ & 106 & 106 & 1.0 \\
\hline $11 b$ & 102 & 102 & 1.0 \\
\hline $11 e$ & 99 & 99 & 1.0 \\
\hline 11f & 103 & 103 & 1.0 \\
\hline $12 \mathbf{a}^{\mathrm{e}}[11]$ & 90 & 27 & 3.4 \\
\hline $\mathbf{1 2} \mathbf{d}^{\mathrm{e}}[11]$ & 42 & 4.0 & 10 \\
\hline $\mathbf{1 2} \mathbf{e}^{\mathrm{e}}[11]$ & 27 & 10 & 2.8 \\
\hline coumarin & $>500$ & $>150$ & - \\
\hline imidazole & $>500$ & $>150$ & - \\
\hline
\end{tabular}

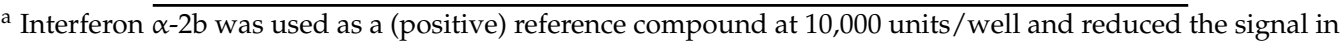
the viral RNA (luciferase) assay to background levels. The values were obtained as the average of triplicate determinations; ${ }^{\mathrm{b}}$ The concentration of a compound with an adverse effect of $50 \%$ was observed on the host cell metabolism, as determined by the MTS method; ${ }^{\mathrm{c}}$ The concentration of a compound at which virus replication was inhibited by $50 \%$ was observed, as determined by real-time quantitative RT-PCR; ${ }^{\mathrm{d}}$ Selectivity index (ratio of $C_{50}$ to $E_{50}$ ); ${ }^{\text {e }}$ Reference known compounds published in [11]. 


\section{Structure-Activity Relationship: Essential Moieties and Functional Groups}

This work established four new sets of conjugated compounds in the family of imidazole-, (1-ribofuranosyl)imidazole-, inosine-, and guanosine-coumarins as shown in Schemes 1-3. All of the conjugates had a $-\mathrm{SCH}_{2}$ - joint to connect a coumarin moiety to an imidazole moiety. The substituents in these conjugated compounds included $\mathrm{F}, \mathrm{Cl}, \mathrm{Br}, \mathrm{Me}$, and $\mathrm{OMe}$. Close examination of their $\mathrm{EC}_{50}$, $\mathrm{CC}_{50}$, and SI values shown in Table 1 allows us to deduce their SAR.

Attachment of the coumarin moiety to the imidazole nucleus generated conjugates with important anti-HCV activity. Successful examples include $3 \mathbf{b}-\mathbf{e}$ with $\mathrm{EC}_{50}=5.1-9.7 \mu \mathrm{M}$ and SI $=8.8-21$. Besides, attachment of a substituent (e.g., $\mathrm{F}, \mathrm{Cl}, \mathrm{Br}$, and $\mathrm{OMe}$ ) to the coumarin nucleus increased the potency and the SI value by a factor of 2.1-5.1 ( $c f .3 \mathbf{b}-\mathbf{e}$ vs. 3a).

An Me group could be introduced onto the imidazole nucleus, while the resultant conjugates without an $\mathrm{N}-\mathrm{H}$ proton maintained a similar order of anti-HCV activity and selectivity ( $c f$. $\mathbf{3 f}$ and $\mathbf{3 g}$ with $\mathrm{EC}_{50}=6.7$ and $15 \mu \mathrm{M}$, respectively; $\mathrm{SI}=7.3$ and 5.1, respectively). On the other hand, introduction of a $\beta$-D-ribofuranosyl moiety to the thiomethylene-linked imidazole-coumarin conjugates led to a triply hybrid compound (i.e., 7a-e), some of which also exhibited anti-HCV activity $\left(\mathrm{EC}_{50}=14\right.$ and $19 \mu \mathrm{M}$ for $\mathbf{7 c}$ and $\mathbf{7 d}$, respectively). In contrast to the ribosylated form at the $\mathrm{N}(1)$ position of the imidazole nucleus, the $\mathrm{N}-\mathrm{H}$ group at that position allowed for an incremental SI value (cf. 3a-e vs. 7a-e). Accordingly, the imidazole nucleus bearing an $\mathrm{H}$ was considered as an ideal core for conjugation with coumarins.

The conjugated compounds with the imidazole nucleus had a higher selectivity than those (i.e., 12a,d,e) [11] with a benzimidazole nucleus as shown below (Figure 2). It is due to lower cytotoxicity associated with the conjugates $3 \mathbf{a}, \mathbf{d}, \mathbf{e}(c f$. 3a $v s$. 12a, 3d vs. 12d and $3 \mathbf{e} v s$. 12e). Moreover, the conjugated compounds bearing a simple imidazole nucleus showed greater anti-HCV activity than the corresponding conjugated compounds bearing an inosine or a guanosine nucleus by one order (cf. $\mathbf{3}$ vs. 9, and $\mathbf{3}$ vs. 11).

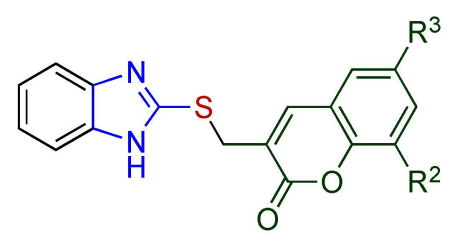

\begin{tabular}{|lll|}
\hline 12 & $\mathrm{R}^{2}:$ & $\mathrm{R}^{3}:$ \\
a & $\mathrm{H}$ & $\mathrm{H}$ \\
d & $\mathrm{H}$ & $\mathrm{Br}$ \\
e & $\mathrm{OMe}$ & $\mathrm{H}$ \\
\hline
\end{tabular}

Figure 2. Structure of benzimidazole-coumarin conjugates.

\section{Experimental Section}

\subsection{General Procedures}

All reactions were carried out in oven-dried glassware $\left(120^{\circ} \mathrm{C}\right)$ under an atmosphere of nitrogen unless indicated otherwise. Dichloromethane, acetone, and methanol were purchased from Mallinckrodt Chemical Co. (Dublin, Ireland). Acetonitrile was purchased from Fischer Scientific Co. (Hampton, NH, USA). Ethyl acetate (EtOAc) and hexanes from Mallinckrodt Chemical Co. were dried and distilled from $\mathrm{CaH}_{2}$. Trimethylsilyl trifluoro-methanesulfonate ( $\left.\mathrm{Me}_{3} \mathrm{SiOTf}\right)$ was purchased from Fluka Chemika (St. Louis, MO, USA). N,O-Bistrimethylsilylacetamide (BTSA) was purchased from Merck \& Co. (Kenilworth, NJ, USA). Aqueous ammonium hydroxide was purchased from J. T. Baker Chemical Co. (Center Valley, PA, USA). $p$-Toluenesulfonic acid monohydrate (PTSA), $1 H$-imidazole-2-thiol (1a), and 1-methyl-imidazole-2-thiol (1) $)$ were purchased from Sigma-Aldrich Chemical Co. (St. Louis, MO, USA). 1,2,3,5-Tetra- $O$-acetyl- $\beta$-D-ribofuranose was purchased from Alfa Aesar Chemical Co. (Ward Hill, MA, USA). 3-(Chloromethyl)coumarins [47] 2a-e, 8-mercaptoinosine 8 [40], and 8-mercaptoguanosine 10 [41], were prepared according to the reported methods. 
Melting points were obtained with a MP-2D melting point apparatus (Fargo, New Taipei City, Taiwan). Analytical thin layer chromatography (TLC) was performed on pre-coated plates (silica gel 60 F-254) purchased from Merck \& Co. (Kenilworth, NJ, USA). Purification by gravity column chromatography was carried out by use of Silicycle (Quebec, QC, Canada) ultra pure silica gel (particle size 40-63 $\mu \mathrm{m}, 230-400$ mesh). High performance liquid chromatography (HPLC) was performed on two Waters 515 HPLC pumps equipped with a Waters $2489 \mathrm{UV} /$ visible detector (Milford, MA, USA) and a Thermo (Waltham, MA, USA) $5 \mu \mathrm{m}$ Hypersil ODS ( $250 \mathrm{~mm} \times 4.6 \mathrm{~mm}$ i.d.). Purity of all compounds was $>98.0 \%$, as checked by HPLC.

Infrared (IR) spectra were measured on a model Spectrum One B spectrophotometer (Perkin-Elmer, Waltham, MA, USA). Absorption intensities are recorded with the following abbreviations: s, strong; $\mathrm{m}$, medium; w, weak. High-resolution mass spectra were obtained by means of a JMS-700 mass spectrometer (JEOL, Tokyo, Japan). Proton NMR spectra were obtained on a Mercury-400 (400 MHz) spectrometer (Varian, Palo Alto, CA, USA) or an AC-400 (400 MHz) spectrometer (Bruker, Billerica, MA, USA) using chloroform- $d$, or dimethylsulfoxide- $d_{6}$ as solvents. Proton NMR chemical shifts are referenced to the $\mathrm{CHCl}_{3}$ singlet $(\delta 7.24 \mathrm{ppm})$, and the center of DMSO- $d_{6}$ quintet $(\delta 2.49 \mathrm{ppm})$. Carbon-13 NMR spectra were recorded on a Varian Mercury-400 (100 MHz) spectrometer or Bruker AC-400 (100 MHz) spectrometer using chloroform- $d$, dimethylsulfoxide- $d_{6}$, or pyridine- $d_{5}$ as solvents. Carbon-13 chemical shifts are referenced to the center of the $\mathrm{CDCl}_{3}$ triplet $(\delta 77.0 \mathrm{ppm})$, the DMSO- $d_{6}$ septet $(\delta 39.5 \mathrm{ppm})$, and the pyridine- $d_{5}$ triplet $(\delta 150.4 \mathrm{ppm})$. Multiplicities are recorded with the following abbreviations: $\mathrm{s}$, singlet; $\mathrm{d}$, doublet; $\mathrm{t}$, triplet; $\mathrm{q}$, quartet; $\mathrm{m}$, multiplet; $J$, coupling constant (hertz).

\subsection{Standard Procedure for the Synthesis of Imidazole-Coumarin Conjugates 3, 7, 9, and $\mathbf{1 1}$}

To a solution containing a thione $(\mathbf{1}, \mathbf{6}, \mathbf{8}$, or $\mathbf{1 0}, 1.0$ equiv) in water $(2.5 \mathrm{~mL})$ and acetonitrile $(1.5 \mathrm{~mL})$ was added saturated aqueous ammonium hydroxide. After the solution was stirred at room temperature for $30 \mathrm{~min}$, a 3-(chloromethyl)coumarin (2, 1.5 equiv) was added and stirring was continued at room temperature for $15 \mathrm{~min}$ to $2.0 \mathrm{~h}$. Acetonitrile therein was removed under reduced pressure and water was further removed under reduced pressure over $\mathrm{P}_{2} \mathrm{O}_{5}$ with a Kügelrohr GKR-51 apparatus (BUCHI, Flawil, Switzerland). The residue was purified by use of column chromatography packed with silica gel to give the desired products with purity of $>98.0 \%$, as determined by HPLC (see Supplementary Materials).

\subsubsection{2-[(Coumarin-3'-yl)methylthio]imidazole (3a)}

The standard procedure was followed by use of $1 \mathrm{H}$-imidazole-2-thiol (1a, $28.6 \mathrm{mg}, 0.286 \mathrm{mmol}$, 1.0 equiv), aqueous ammonium hydroxide $(0.25 \mathrm{~mL})$, and 3-(chloromethyl)coumarin $(2 \mathrm{a}, 66.7 \mathrm{mg}$, $0.343 \mathrm{mmol}, 1.2$ equiv). After the solution was stirred at room temperature for $2.0 \mathrm{~h}$ and then worked up, the residue was purified by use of column chromatography (5.0\% methanol in dichloromethane as the eluent) to give $3 \mathrm{a}(63.4 \mathrm{mg}, 0.246 \mathrm{mmol})$ in $86 \%$ yield as a white solid: $\mathrm{mp}$ (recrystallized from $\mathrm{EtOH}) 252.0-252.8^{\circ} \mathrm{C} ;{ }^{1} \mathrm{H}-\mathrm{NMR}\left(\mathrm{CDCl}_{3}, 400 \mathrm{MHz}\right) \delta 7.58(\mathrm{~s}, 1 \mathrm{H}, \mathrm{O}=\mathrm{C}-\mathrm{C}=\mathrm{CH}), 7.39(\mathrm{~s}, 2 \mathrm{H}, 2 \times \mathrm{NCH})$, 7.35-7.29 (m, 2H, $2 \times \mathrm{ArH}), 7.14-7.10(\mathrm{~m}, 2 \mathrm{H}, 2 \times \mathrm{ArH}), 4.33\left(\mathrm{~s}, 2 \mathrm{H}, \mathrm{SCH}_{2}\right) ;{ }^{13} \mathrm{C}-\mathrm{NMR}$ (pyridine- $d_{5}$, $100 \mathrm{MHz}) \delta 160.77$ (C=O), 153.77, 140.38, 143.12, 139.37, 131.37, 128.18, 126.19, 124.58, 119.72, 116.42, $34.86\left(\mathrm{SCH}_{2}\right)$; IR (KBr) 3307 (br, NH), $1713(\mathrm{~s}, \mathrm{C}=\mathrm{O}), 1616(\mathrm{~m}), 1587(\mathrm{~m}), 1122(\mathrm{~m}) \mathrm{cm}^{-1}$; $\mathrm{MS}_{\left(\mathrm{FAB}^{+}\right)}$ $m / z 259\left(\mathrm{MH}^{+}, 27\right), 154$ (100), 137 (57), 107 (24), 89 (24). HRMS $m / z$ calcd for $\mathrm{C}_{13} \mathrm{H}_{10} \mathrm{~N}_{2} \mathrm{O}_{2} \mathrm{~S}: 258.0463$, found: 258.0462 .

\subsubsection{2-[(6'-Fluorocoumarin-3'-yl)methylthio]imidazole (3b)}

The standard procedure was followed by use of $1 \mathrm{H}$-imidazole-2-thiol (1a, $29.1 \mathrm{mg}, 0.291 \mathrm{mmol}$, 1.0 equiv), aqueous ammonium hydroxide $(0.25 \mathrm{~mL})$, and 3-(chloromethyl)-6-fluorocoumarin $(\mathbf{2 b}, 74.2 \mathrm{mg}$, $0.349 \mathrm{mmol}, 1.2$ equiv). After the solution was stirred at room temperature for $2.0 \mathrm{~h}$ and then worked up, the residue was purified by use of column chromatography $(5.0 \%$ methanol in dichloromethane as 
the eluent) to give $3 \mathbf{b}(59.9 \mathrm{mg}, 0.218 \mathrm{mmol})$ in $75 \%$ yield as a white solid: $\mathrm{mp}$ (recrystallized from EtOH) 258.6-259.4 ${ }^{\circ} \mathrm{C} ;{ }^{1} \mathrm{H}-\mathrm{NMR}$ (DMSO- $\left.d_{6}, 400 \mathrm{MHz}\right) \delta 7.58(\mathrm{~s}, 1 \mathrm{H}, \mathrm{O}=\mathrm{C}-\mathrm{C}=\mathrm{CH}), 7.51-7.43(\mathrm{~m}, 3 \mathrm{H}$, $3 \times \mathrm{ArH}), 7.13(\mathrm{~s}, 1 \mathrm{H}, 1 \times \mathrm{NCH}), 6.95(\mathrm{~s}, 1 \mathrm{H}, 1 \times \mathrm{NCH}), 3.99\left(\mathrm{~s}, 2 \mathrm{H}, \mathrm{SCH}_{2}\right) ;{ }^{13} \mathrm{C}-\mathrm{NMR}$ (pyridine- $d_{5}$, $100 \mathrm{MHz}) \delta 160.45$ (C=O), 160.01, 157.61, 139.36, 127.33, 125.10, 120.56, 118.62, 118.37, 118.14, 113.54, 113.30, $34.71\left(\mathrm{SCH}_{2}\right)$; IR (KBr) 3306 (br, NH), 1713 (s, C=O), $1619(\mathrm{~m}), 1504(\mathrm{~m}), 1188(\mathrm{~m}) \mathrm{cm}^{-1}$; MS $\left(\mathrm{FAB}^{+}\right) m / z 277\left(\mathrm{MH}^{+}, 19\right), 157$ (31), 137 (22), 107 (9), 79 (100), 78 (23). HRMS $m / z$ calcd for $\mathrm{C}_{13} \mathrm{H}_{9} \mathrm{~N}_{2} \mathrm{O}_{2} \mathrm{FS}: 276.0369$, found: 276.0368 .

\subsubsection{2-[(6'-Chlorocoumarin-3'-yl)methylthio]imidazole (3c)}

The standard procedure was followed by use of $1 \mathrm{H}$-imidazole-2-thiol (1a, $25.6 \mathrm{mg}, 0.256 \mathrm{mmol}$, 1.0 equiv), aqueous ammonium hydroxide $(0.25 \mathrm{~mL})$, and 3-(chloromethyl)-6-chlorocoumarin (2c, $70.3 \mathrm{mg}, 0.307 \mathrm{mmol}, 1.2$ equiv). After the solution was stirred at room temperature for $2.0 \mathrm{~h}$ and then worked up, the residue was purified by use of column chromatography $(5.0 \%$ methanol in dichloromethane as the eluent) to give $3 \mathrm{c}(48.6 \mathrm{mg}, 0.166 \mathrm{mmol})$ in $65 \%$ yield as a white solid: $\mathrm{mp}$ (recrystallized from EtOH) 266.2-270.0 ${ }^{\circ} \mathrm{C} ;{ }^{1} \mathrm{H}-\mathrm{NMR}$ (DMSO- $\left.d_{6}, 400 \mathrm{MHz}\right) \delta 7.73(\mathrm{~s}, 1 \mathrm{H}, \mathrm{ArH}), 7.60(\mathrm{~d}$, $1 \mathrm{H}, J=8.8 \mathrm{~Hz}, \mathrm{ArH}), 7.57(\mathrm{~s}, 1 \mathrm{H}, \mathrm{O}=\mathrm{C}-\mathrm{C}=\mathrm{CH}), 7.43(\mathrm{~d}, 1 \mathrm{H}, J=8.8 \mathrm{~Hz}, \mathrm{ArH}), 7.13(\mathrm{~s}, 1 \mathrm{H}, \mathrm{NCH}), 6.96(\mathrm{~s}$, $1 \mathrm{H}, \mathrm{NCH}), 3.98\left(\mathrm{~s}, 2 \mathrm{H}, \mathrm{SCH}_{2}\right) ;{ }^{13} \mathrm{C}-\mathrm{NMR}$ (pridine- $\left.d_{5}, 100 \mathrm{MHz}\right) \delta 160.26(\mathrm{C}=\mathrm{O}), 152.08,139.16,139.08$, 131.06, 129.28, 127.42, 125.11, 122.97, 120.85, 118.05, $34.64\left(\mathrm{SCH}_{2}\right)$; IR (KBr) 3309 (br, NH), 1714 (s, C=O), 1615 (m), 1504 (m), 1189 (m) cm ${ }^{-1}$; MS (FAB $\left.{ }^{+}\right) \mathrm{m} / z 293\left(\mathrm{MH}^{+}, 14\right), 154$ (100), 137 (57), 107 (22), 89 (23), 77 (20). HRMS $m / z$ calcd for $\mathrm{C}_{13} \mathrm{H}_{9} \mathrm{~N}_{2} \mathrm{O}_{2}$ ClS: 292.0073, found: 292.0074.

\subsubsection{2-[(6'-Bromocoumarin-3'-yl)methylthio]imidazole (3d)}

The standard procedure was followed by use of $1 \mathrm{H}$-imidazole-2-thiol (1a, $28.8 \mathrm{mg}, 0.288 \mathrm{mmol}$, 1.0 equiv), aqueous ammonium hydroxide $(0.25 \mathrm{~mL}$ ), and 3-(chloromethyl)-6-bromocoumarin $(2 \mathrm{~d}, 94.5 \mathrm{mg}$, $0.345 \mathrm{mmol}, 1.2$ equiv). After the solution was stirred at room temperature for $2.0 \mathrm{~h}$ and then worked up, the residue was purified by use of column chromatography $(5.0 \%$ methanol in dichloromethane as the eluent) to give $3 \mathbf{d}(71.8 \mathrm{mg}, 0.213 \mathrm{mmol})$ in $74 \%$ yield as a white solid: $\mathrm{mp}$ (recrystallized from $\mathrm{EtOH}) 276.8-277.4{ }^{\circ} \mathrm{C} ;{ }^{1} \mathrm{H}-\mathrm{NMR}\left(\mathrm{CDCl}_{3}, 400 \mathrm{MHz}\right) \delta 7.84(\mathrm{~d}, J=2.4 \mathrm{~Hz}, 1 \mathrm{H}, \mathrm{ArH}), 7.71(\mathrm{dd}, J=8.8$, $2.4 \mathrm{~Hz}, 1 \mathrm{H}, \mathrm{ArH}), 7.56(\mathrm{~s}, 1 \mathrm{H}, \mathrm{O}=\mathrm{C}-\mathrm{C}=\mathrm{CH}), 7.37(\mathrm{~d}, J=8.8 \mathrm{~Hz}, 1 \mathrm{H}, \mathrm{ArH}), 7.04(\mathrm{~s}, 2 \mathrm{H}, 2 \times \mathrm{NCH}), 3.98(\mathrm{~s}$, $\left.2 \mathrm{H}, \mathrm{SCH}_{2}\right) ;{ }^{13} \mathrm{C}-\mathrm{NMR}$ (pyridine- $\left.d 5 / \mathrm{DMSO}-d_{6}, 100 \mathrm{MHz}\right) \delta 160.23(\mathrm{C}=\mathrm{O}), 152.09,139.40,137.95,134.26$, 130.28, 126.27, 126.07, 120.93, 118.52, 116.71, $34.38\left(\mathrm{SCH}_{2}\right)$; IR (KBr) 3307 (br, NH), 1714 (s, C=O), 1620 (m), 1504 (m), 1189 (m), $1123(\mathrm{~m}) \mathrm{cm}^{-1}$; MS (FAB $\left.{ }^{+}\right) \mathrm{m} / z 337\left(\mathrm{MH}^{+}, 18\right), 154$ (100), 137 (55), 107 (24), 89 (29), 77 (21). HRMS $m / z$ calcd for $\mathrm{C}_{13} \mathrm{H}_{9} \mathrm{~N}_{2} \mathrm{O}_{2} \mathrm{BrS}$ : 335.9568, found: 335.9649 .

\subsubsection{2-[(8'-Methoxycoumarin-3'-yl)methylthio]imidazole (3e)}

The standard procedure was followed by use of $1 \mathrm{H}$-imidazole-2-thiol (1a, $28.7 \mathrm{mg}, 0.287 \mathrm{mmol}$, 1.0 equiv), aqueous ammonium hydroxide $(0.25 \mathrm{~mL})$, and 3-(chloromethyl)-8-methoxycoumarin (2e, $76.6 \mathrm{mg}, 0.344 \mathrm{mmol}, 1.2$ equiv). After the solution was stirred at room temperature for $2.0 \mathrm{~h}$ and then worked up, the residue was purified by use of column chromatography $(5.0 \%$ methanol in dichloromethane as the eluent) to give $3 \mathbf{e}(66.3 \mathrm{mg}, 0.229 \mathrm{mmol})$ in $80 \%$ yield as a white solid: $\mathrm{mp}$ (recrystallized from EtOH) 269.8-270.6 ${ }^{\circ} \mathrm{C} ;{ }^{1} \mathrm{H}-\mathrm{NMR}$ (DMSO- $\left.d_{6}, 400 \mathrm{MHz}\right) \delta 7.55(\mathrm{~s}, 1 \mathrm{H}, \mathrm{O}=\mathrm{C}-\mathrm{C}=\mathrm{CH}$ ), 7.31-7.21 (m, 2H, ArH), 7.10-7.09 (m, 1H, ArH), 7.08 (s, 1H, NCH), 6.97 (s, 1H, NCH), 3.98 (s, 2H, $\left.\mathrm{SCH}_{2}\right), 3.89\left(\mathrm{~s} 3 \mathrm{H}, \mathrm{OCH}_{3}\right) ;{ }^{13} \mathrm{C}-\mathrm{NMR}$ (pyridine- $\left.d_{5} / \mathrm{DMSO}_{-} d_{6}, 100 \mathrm{MHz}\right) \delta 160.45(\mathrm{C}=\mathrm{O}), 146.80,142.83$, $140.69,138.74,125.60,124.54,122.96,119.91,119.71,119.36,113.62,55.93\left(\mathrm{OCH}_{3}\right), 34.52\left(\mathrm{SCH}_{2}\right) ; \mathrm{IR}(\mathrm{KBr})$ 3307 (br, NH), 1713 (s, C=O), 1615 (m), 1504 (m), 1189 (m) cm ${ }^{-1}$; MS (FAB $\left.{ }^{+}\right) \mathrm{m} / z 289\left(\mathrm{MH}^{+}, 15\right), 154$ (100), 137 (52), 107 (28), 89 (23), 77 (24). HRMS $m / z$ calcd for $\mathrm{C}_{14} \mathrm{H}_{12} \mathrm{~N}_{2} \mathrm{O}_{3} \mathrm{~S}: 288.0569$, found: 288.0570.

\subsubsection{1-Methyl-2-[(coumarin-3'-yl)methylthio]imidazole (3f)}

The standard procedure was followed by use of 1-methyl-imidazole-2-thiol (1b, $33.2 \mathrm{mg}$, $0.291 \mathrm{mmol}, 1.0$ equiv), aqueous ammonium hydroxide $(0.25 \mathrm{~mL})$, and 3-(chloromethyl)coumarin (2a, 
$85.1 \mathrm{mg}, 0.437 \mathrm{mmol}, 1.5$ equiv). After the solution was stirred at room temperature for $2.0 \mathrm{~h}$ and then worked up, the residue was purified by use of column chromatography $(40 \%$ dichloromethane in EtOAc as the eluent) to give $3 \mathrm{f}(54.9 \mathrm{mg}, 0.201 \mathrm{mmol})$ in $69 \%$ yield as a white solid: $\mathrm{mp}$ (recrystallized from EtOH) 244.2-244.8 ${ }^{\circ} \mathrm{C} ;{ }^{1} \mathrm{H}-\mathrm{NMR}\left(\mathrm{CDCl}_{3}, 400 \mathrm{MHz}\right) \delta 7.53(\mathrm{~s}, 1 \mathrm{H}, \mathrm{O}=\mathrm{C}-\mathrm{C}=\mathrm{CH}), 7.45(\mathrm{t}, J=7.2 \mathrm{~Hz}$, $1 \mathrm{H}, \mathrm{ArH}), 7.34(\mathrm{~s}, J=7.8 \mathrm{~Hz}, 1 \mathrm{H}, \mathrm{ArH}), 7.28-7.19(\mathrm{~m}, 2 \mathrm{H}, 2 \times \mathrm{ArH}), 7.05(\mathrm{~s}, 1 \mathrm{H}, \mathrm{NCH}), 6.85(\mathrm{~s}, 1 \mathrm{H}$, $\mathrm{NCH}), 4.12\left(\mathrm{~s}, 2 \mathrm{H}, \mathrm{SCH}_{2}\right), 3.47\left(\mathrm{~s}, 3 \mathrm{H}, \mathrm{NCH}_{3}\right) ;{ }^{13} \mathrm{C}-\mathrm{NMR}\left(\mathrm{CDCl}_{3}, 100 \mathrm{MHz}\right) \delta 160.82(\mathrm{C}=\mathrm{O}), 153.45$, 140.55, 131.3129.47, 127.77, 125.01, 124.45, 122.57, 119.15, 116.67, 116.47, $33.92\left(\mathrm{SCH}_{2}\right), 33.20\left(\mathrm{CH}_{3}\right) ; \mathrm{IR}$

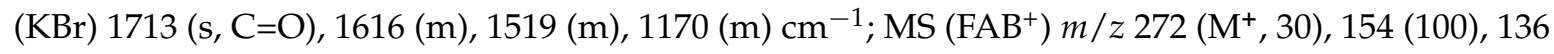
(77), 89 (33), 77 (20), 55 (60); HRMS $m / z$ calcd for $\mathrm{C}_{14} \mathrm{H}_{12} \mathrm{~N}_{2} \mathrm{O}_{2} \mathrm{~S}: 272.0619$, found: 272.0620 .

\subsubsection{1-Methyl-2-[(6'-chlorocoumarin-3'-yl)methylthio]imidazole (3g)}

The standard procedure was followed by use of 1-methyl-imidazole-2-thiol (1b, $36.2 \mathrm{mg}$, $0.317 \mathrm{mmol}, 1.0$ equiv), aqueous ammonium hydroxide $(0.25 \mathrm{~mL})$, and 3-(chloromethyl)-6chlorocoumarin (2c, $109 \mathrm{mg}, 0.476 \mathrm{mmol}, 1.5$ equiv). After the solution was stirred at room temperature for $2.0 \mathrm{~h}$ and then worked up, the residue was purified by use of column chromatography $(40 \%$ dichloromethane in EtOAc as the eluent) to give $3 \mathrm{~g}(70.5 \mathrm{mg}, 0.231 \mathrm{mmol})$ in $73 \%$ yield as a white solid: $\mathrm{mp}$ (recrystallized from EtOH) $256.2-257.2{ }^{\circ} \mathrm{C} ;{ }^{1} \mathrm{H}-\mathrm{NMR}\left(\mathrm{CDCl}_{3}, 400 \mathrm{MHz}\right) \delta 7.51$ (s, $\left.1 \mathrm{H}, \mathrm{O}=\mathrm{C}-\mathrm{C}=\mathrm{CH}\right)$, $7.40(\mathrm{~d}, J=8.8 \mathrm{~Hz}, 1 \mathrm{H}, \mathrm{ArH}), 7.34(\mathrm{~s}, 1 \mathrm{H}, \mathrm{ArH}), 7.22(\mathrm{~d}, J=8.8 \mathrm{~Hz}, 1 \mathrm{H}, \operatorname{ArH}), 7.06(\mathrm{~s}, 1 \mathrm{H}, \mathrm{NCH}), 6.87(\mathrm{~s}$, $1 \mathrm{H}, \mathrm{NCH}), 4.12\left(\mathrm{~s}, 2 \mathrm{H}, \mathrm{SCH}_{2}\right), 3.49\left(\mathrm{~s}, 3 \mathrm{H}, \mathrm{NCH}_{3}\right) ;{ }^{13} \mathrm{C}-\mathrm{NMR}\left(\mathrm{CDCl}_{3}, 100 \mathrm{MHz}\right) \delta 160.27(\mathrm{C}=\mathrm{O}), 151.80$, $140.40,139.27,131.23,129.73,129.49,126.98,126.38,122.66,120.22,117.92,33.56\left(\mathrm{SCH}_{2}\right), 33.20\left(\mathrm{CH}_{3}\right) ; \mathrm{IR}$ (KBr) 1705 (s, C=O), 1615 (m), 1518 (m), 1233 (m) cm ${ }^{-1}$; MS (FAB $\left.{ }^{+}\right) \mathrm{m} / z 307\left(\mathrm{MH}^{+}, 100\right), 154$ (66), 136 (59), 77 (30), 55 (35), 77 (20); HRMS $m / z$ calcd for $\mathrm{C}_{14} \mathrm{H}_{11} \mathrm{~N}_{2} \mathrm{O}_{2} \mathrm{ClS}$ : 306.0230, found: 306.0233.

\subsubsection{1-(2', 3', $5^{\prime}$-Tri-O-acetyl- $\beta$-D-ribofuranos-1'-yl)imidazole-2-thiol (5)}

To a solution of $1 \mathrm{H}$-imidazole-2-thiol (1a, $375 \mathrm{mg}$, $3.74 \mathrm{mmol}, 1.0$ equiv) in dry acetonitrile $(30 \mathrm{~mL})$ was added BTSA $(1.20 \mathrm{~mL}, 4.91 \mathrm{mmol}, 1.3$ equiv) under nitrogen atmosphere according to the Vorbrüggen procedure [43]. After the solution was stirred at $60{ }^{\circ} \mathrm{C}$ for $30 \mathrm{~min}$, 1,2,3,5-tetra-O-acetyl- $\beta$-D-ribofuranose $\left(4,1.25 \mathrm{~g}, 3.93 \mathrm{mmol}, 1.1\right.$ equiv) and $\mathrm{Me}_{3} \mathrm{SiOTf}(0.711 \mathrm{~mL}$, $3.93 \mathrm{mmol}, 1.1$ equiv) were added in sequence. The reaction mixture was heated to $80^{\circ} \mathrm{C}$ and stirred for $18 \mathrm{~h}$. Excess solvent was removed under reduced pressure, and the residue was treated with $20 \%$ aqueous $\mathrm{NaHCO}_{3}$ solution $(30 \mathrm{~mL})$. The aqueous layer was extracted with ethyl acetate $(3 \times 25 \mathrm{~mL})$. The combined organic layers were washed with brine $(30 \mathrm{~mL})$, dried over $\mathrm{MgSO}_{4}(\mathrm{~s})$, filtered, and concentrated under reduced pressure to afford a residue, which was purified by use of column chromatography (20\% hexanes in EtOAc as the eluent) to give $5(698.4 \mathrm{mg}, 1.945 \mathrm{mmol})$ in $52 \%$ yield. ${ }^{1} \mathrm{H}-\mathrm{NMR}\left(\mathrm{CDCl}_{3}, 400 \mathrm{MHz}\right) \delta 6.90(\mathrm{~s}, 1 \mathrm{H}, \mathrm{NCH}), 6.72(\mathrm{~s}, 1 \mathrm{H}, \mathrm{NCH}), 6.47\left(\mathrm{~s}, 1 \mathrm{H}, \mathrm{H}-1{ }^{\prime \prime}\right), 5.44(\mathrm{t}, J=5.2 \mathrm{~Hz}$, $\left.1 \mathrm{H}, \mathrm{H}-2^{\prime \prime}\right), 5.31\left(\mathrm{t}, J=5.2 \mathrm{~Hz}, 1 \mathrm{H}, \mathrm{H}-3^{\prime \prime}\right), 4.38-4.36\left(\mathrm{~m}, 1 \mathrm{H}, \mathrm{H}-4^{\prime \prime}\right), 4.33-4.28\left(\mathrm{~m}, 2 \mathrm{H}, 2 \times \mathrm{H}-5^{\prime \prime}\right), 2.13$ $\left(\mathrm{s}, 3 \mathrm{H}, \mathrm{CO}_{2} \mathrm{CH}_{3}\right), 2.11\left(\mathrm{~s}, 3 \mathrm{H}, \mathrm{CO}_{2} \mathrm{CH}_{3}\right), 2.09\left(\mathrm{~s}, 3 \mathrm{H}, \mathrm{CO}_{2} \mathrm{CH}_{3}\right)$. These data are consistent with those reported [48].

\subsubsection{1- $\beta$-D-Ribofuranosyl-imidazole-2-thiol (6)}

To a solution containing 5 ( $82.6 \mathrm{mg}, 0.230 \mathrm{mmol}, 1.0$ equiv) in methanol $(10 \mathrm{~mL})$ was added potassium carbonate $(31.9 \mathrm{mg}, 0.231 \mathrm{mmol}, 1.0$ equiv) at room temperature. After the solution was stirred at $0^{\circ} \mathrm{C}$ for $12 \mathrm{~h}$, it was concentrated under reduced pressure. To the residue was added saturated aqueous $\mathrm{NH}_{4} \mathrm{Cl}(20 \mathrm{~mL})$, which was extracted with $\mathrm{CHCl}_{3}(3 \times 20 \mathrm{~mL})$. The combined organic layers were washed with brine $(20 \mathrm{~mL})$, dried over $\mathrm{MgSO}_{4}(\mathrm{~s})$, filtered, and concentrated under reduced pressure. The residue was then purified by use of column chromatography $(10 \% \mathrm{MeOH}$ in EtOAc as the eluent) to give $6(49.1 \mathrm{mg}, 0.212 \mathrm{mmol})$ in $92 \%$ yield. ${ }^{1} \mathrm{H}-\mathrm{NMR}$ (DMSO- $\left.d_{6}, 400 \mathrm{MHz}\right) \delta 7.29(\mathrm{~s}, 1 \mathrm{H}$, $\mathrm{NCH}), 6.91(\mathrm{~s}, 1 \mathrm{H}, \mathrm{NCH}), 6.02\left(\mathrm{~s}, 1 \mathrm{H}, \mathrm{H}-1^{\prime \prime}\right), 5.27(\mathrm{~d}, J=6.6 \mathrm{~Hz}, 1 \mathrm{H}, \mathrm{OH}), 5.03(\mathrm{~d}, J=4.0 \mathrm{~Hz}, 1 \mathrm{H}, \mathrm{OH})$, $4.98(\mathrm{t}, J=5.2 \mathrm{~Hz}, 1 \mathrm{H}, \mathrm{OH}), 4.07-4.04\left(\mathrm{~m}, 1 \mathrm{H}, \mathrm{H}-2^{\prime \prime}\right), 4.03-3.99$ (m, 1H, H-3"), 3.83-3.81 (m, 1H, H-4"), 3.63-3.53 (m, 2H, $\left.2 \times \mathrm{H}-5^{\prime \prime}\right)$. These data are consistent with those reported [48]. 


\subsubsection{1-( $\beta$-D-Ribofuranos-1"'-yl)-2-[(coumarin-3'-yl)methylthio]imidazole (7a)}

The standard procedure was followed by use of 1- $\beta$-D-ribofuranosyl-imidazole-2-thiol $(6,43.1 \mathrm{mg}$, $0.186 \mathrm{mmol}, 1.0$ equiv), aqueous ammonium hydroxide $(0.25 \mathrm{~mL})$, and 3-(chloromethyl)coumarin (2a, $43.4 \mathrm{mg}, 0.223 \mathrm{mmol}, 1.2$ equiv). After the solution was stirred at room temperature for $2.0 \mathrm{~h}$ and then worked up, the residue was purified by use of column chromatography $(10 \% \mathrm{MeOH}$ in dichloromethane as the eluent) to give $7 \mathrm{a}(53.7 \mathrm{mg}, 0.165 \mathrm{mmol})$ in $74 \%$ yield as a white solid: $\mathrm{mp}$ (recrystallized from EtOH) $164.6-165.4{ }^{\circ} \mathrm{C} ;{ }^{1} \mathrm{H}-\mathrm{NMR}$ (DMSO- $\left.d_{6}, 400 \mathrm{MHz}\right) \delta 7.66(\mathrm{~s}, 1 \mathrm{H}, \mathrm{O}=\mathrm{C}-\mathrm{C}=\mathrm{CH})$, 7.58-7.54 (m, 2H, $2 \times \mathrm{ArH}), 7.49(\mathrm{~s}, 1 \mathrm{H}, \mathrm{NCH}), 7.38(\mathrm{~d}, J=8.4 \mathrm{~Hz}, 1 \mathrm{H}, \mathrm{ArH}), 7.30(\mathrm{t}, J=7.6 \mathrm{~Hz}, 1 \mathrm{H}$, ArH), 6.99 (s, 1H, NCH), 5.67 (d, J = 7.2 Hz, 1H, H-1"), 5.37 (d, J = 6.4 Hz, 1H, OH), 5.17 (d, J = 4.4 Hz, $1 \mathrm{H}, \mathrm{OH}), 4.93(\mathrm{t}, J=5.2 \mathrm{~Hz}, 1 \mathrm{H}, \mathrm{OH}), 4.16-4.11\left(\mathrm{~m}, 1 \mathrm{H}, \mathrm{H}-2^{\prime \prime}\right), 4.04\left(\mathrm{~s}, 2 \mathrm{H}, \mathrm{SCH}_{2}\right), 3.99-3.98(\mathrm{~m}, 1 \mathrm{H}$, H-3"), 3.78-3.76 (m, 1H, H-4"), 3.43-3.39 (m, 2H, $\left.2 \times \mathrm{H}-5{ }^{\prime \prime}\right) ;{ }^{13} \mathrm{C}-\mathrm{NMR}$ (DMSO-d, $\left.100 \mathrm{MHz}\right) \delta 160.03$ (C=O), 151.94, 140.67, 139.65, 131.57, 129.62, 128.20, 124.59, 124.44, 119.54, 118.97, 116.00, 88.13, 85.58, 75.10, 70.55, 61.36, $34.27\left(\mathrm{SCH}_{2}\right)$; IR (KBr) 3387 (br, OH), 1698 (s, C=O), 1609 (m), 1457 (m), $1111(\mathrm{~m})$ $\mathrm{cm}^{-1}$; MS (FAB $\left.{ }^{+}\right) \mathrm{m} / z 391\left(\mathrm{MH}^{+}, 66\right), 154$ (100), 137 (54), 77 (33); HRMS m/z calcd for $\mathrm{C}_{18} \mathrm{H}_{18} \mathrm{~N}_{2} \mathrm{O}_{6} \mathrm{~S}$ : 390.0886, found: 390.0891 .

\subsubsection{1-( $\beta$-D-Ribofuranos-1"'-yl)-2-[(6'-fluorocoumarin-3'-yl)methylthio]imidazole (7b)}

The standard procedure was followed by use of 1- $\beta$-D-ribofuranosyl-imidazole-2-thiol (6, $44.9 \mathrm{mg}, 0.193 \mathrm{mmol}, 1.0$ equiv), aqueous ammonium hydroxide (0.25 mL), and 3-(chloromethyl)-6fluorocoumarin ( $\mathbf{2 b}, 49.3 \mathrm{mg}, 0.232 \mathrm{mmol}, 1.2$ equiv). After the solution was stirred at room temperature for $2.0 \mathrm{~h}$ and then worked up, the residue was purified by use of column chromatography $(10 \% \mathrm{MeOH}$ in dichloromethane as the eluent) to give $7 \mathbf{b}(62.9 \mathrm{mg}, 0.154 \mathrm{mmol})$ in $80 \%$ yield as a white solid: $\mathrm{mp}$ (recrystallized from EtOH) $171.2-172.4{ }^{\circ} \mathrm{C} ;{ }^{1} \mathrm{H}-\mathrm{NMR}$ (DMSO- $\left.d_{6}, 400 \mathrm{MHz}\right) \delta 7.62(\mathrm{~s}, 1 \mathrm{H}, \mathrm{O}=\mathrm{C}-\mathrm{C}=\mathrm{CH})$, 7.50 (s, 1H, ArH), 7.47-7.42 (m, 3H, $2 \times \mathrm{ArH}+\mathrm{NCH}), 7.00(\mathrm{~s}, 1 \mathrm{H}, \mathrm{NCH}), 5.65\left(\mathrm{~d}, J=6.4 \mathrm{~Hz}, 1 \mathrm{H}, \mathrm{H}-1^{\prime \prime}\right)$, $5.36(\mathrm{~d}, J=6.8 \mathrm{~Hz}, 1 \mathrm{H}, \mathrm{OH}), 5.18(\mathrm{~d}, J=7.6 \mathrm{~Hz}, 1 \mathrm{H}, \mathrm{OH}), 4.94(\mathrm{t}, J=5.2 \mathrm{~Hz}, 1 \mathrm{H}, \mathrm{OH}), 4.16-4.11(\mathrm{~m}$, 1H, H-2") 4.03 (s, 2H, SCH ${ }_{2}$, 4.00-3.97 (m, 1H, H-3") , 3.77-3.74 (m, 1H, H-4") , 3.42-3.38 (m, $2 \mathrm{H}, 2 \times$ H-5"); ${ }^{13} \mathrm{C}-\mathrm{NMR}\left(\mathrm{CDCl}_{3}, 100 \mathrm{MHz}\right) \delta 159.73$ (C=O), 149.28, 139.60, 139.51, 129.64, 125.67, 119.97, 119.52, $118.78,118.54,117.96,113.49,88.08,85.54,75.01,70.49,61.32,34.22\left(\mathrm{SCH}_{2}\right)$; IR (KBr) $3388(\mathrm{br}, \mathrm{OH}), 1694$ (s, C=O), 1580 (m), 1489 (m), 1265 (m), 1078 (m) cm ${ }^{-1}$; MS (FAB ${ }^{+}$) m/z $409\left(\mathrm{MH}^{+}, 54\right), 154$ (100), 137 (57), 77 (31), 55 (66); HRMS $m / z$ calcd for $\mathrm{C}_{18} \mathrm{H}_{17} \mathrm{~N}_{2} \mathrm{O}_{6} \mathrm{FS}: 408.0791$, found: 408.0794 .

\subsubsection{1-( $\beta$-D-Ribofuranos-1"'-yl)-2-[(6'-chlorocoumarin-3'-yl)methylthio]imidazole (7c)}

The standard procedure was followed by use of 1- $\beta$-D-ribofuranosyl-imidazole-2-thiol (6, $44.6 \mathrm{mg}, 0.192 \mathrm{mmol}, 1.0$ equiv), aqueous ammonium hydroxide (0.25 mL), and 3-(chloromethyl)6-chlorocoumarin (2c, $52.8 \mathrm{mg}, 0.231 \mathrm{mmol}, 1.2 \mathrm{equiv})$. After the solution was stirred at room temperature for $2.0 \mathrm{~h}$ and then worked up, the residue was purified by use of column chromatography (10\% MeOH in dichloromethane as the eluent) to give $7 \mathrm{c}(61.2 \mathrm{mg}, 0.144 \mathrm{mmol}) \mathrm{in} 75 \%$ yield as a white solid: mp (recrystallized from EtOH) $178.8-179.6{ }^{\circ} \mathrm{C} ;{ }^{1} \mathrm{H}-\mathrm{NMR}$ (DMSO-d $\left.6,400 \mathrm{MHz}\right) \delta 7.69(\mathrm{~s}, 1 \mathrm{H}$, $\mathrm{O}=\mathrm{C}-\mathrm{C}=\mathrm{CH}), 7.60(\mathrm{~s}, 1 \mathrm{H}, \mathrm{ArH}), 7.59-7.57(\mathrm{~m}, 2 \mathrm{H}, 2 \times \mathrm{ArH}), 7.49(\mathrm{~s}, 1 \mathrm{H}, \mathrm{NCH}), 7.41(\mathrm{~d}, J=8.8 \mathrm{~Hz}, 1 \mathrm{H}$, ArH), $7.00(\mathrm{~s}, 1 \mathrm{H}, \mathrm{NCH}), 5.65\left(\mathrm{~d}, J=6.4 \mathrm{~Hz}, 1 \mathrm{H}, \mathrm{H}-1^{\prime \prime}\right), 5.34(\mathrm{~d}, J=6.4 \mathrm{~Hz}, 1 \mathrm{H}, \mathrm{OH}), 5.16(\mathrm{~d}, J=4.8 \mathrm{~Hz}$, $1 \mathrm{H}, \mathrm{OH}), 4.92(\mathrm{t}, J=5.2 \mathrm{~Hz}, 1 \mathrm{H}, \mathrm{OH}), 4.15-4.11\left(\mathrm{~m}, 1 \mathrm{H}, \mathrm{H}-2^{\prime \prime}\right), 4.02\left(\mathrm{~s}, 2 \mathrm{H}, \mathrm{SCH}_{2}\right), 4.00-3.97(\mathrm{~m}, 1 \mathrm{H}$, H-3") , 3.77-3.74 (m, 1H, H-4"), 3.41-3.38 (m, 2H, $\left.2 \times \mathrm{H}-5^{\prime \prime}\right) ;{ }^{13} \mathrm{C}-\mathrm{NMR}\left(\mathrm{CDCl}_{3}, 100 \mathrm{MHz}\right) \delta 159.53$ $(\mathrm{C}=\mathrm{O}), 151.54,139.44,139.31,131.05,129.67,128.27,127.17,125.75,120.38,119.54,117.98,88.07,85.55$, 75.01, 70.50, 61.31, $34.31\left(\mathrm{SCH}_{2}\right)$; IR (KBr) 3399 (br, OH), 1695 (s, C=O), 1615 (m), 1580 (m), 1441 (m), $1265(\mathrm{~m}), 1173(\mathrm{~m}) \mathrm{cm}^{-1}$; MS (FAB $\left.{ }^{+}\right) \mathrm{m} / z 425\left(\mathrm{MH}^{+}, 55\right), 154$ (100), 137 (53), 77 (35), 55 (61); HRMS m/z calcd for $\mathrm{C}_{18} \mathrm{H}_{17} \mathrm{~N}_{2} \mathrm{O}_{6} \mathrm{ClS}$ : 424.0496 , found: 424.0580 . 


\subsubsection{1-( $\beta$-D-Ribofuranos-1"'-yl)-2-[(6'-bromocoumarin-3'-yl)methylthio]imidazole (7d)}

The standard procedure was followed by use of 1- $\beta$-D-ribofuranosyl-imidazole-2-thiol (6, $47.2 \mathrm{mg}, 0.203 \mathrm{mmol}, 1.0$ equiv), aqueous ammonium hydroxide $(0.25 \mathrm{~mL})$, and 3-(chloromethyl)6-bromocoumarin ( $2 \mathrm{~d}, 66.7 \mathrm{mg}, 0.244 \mathrm{mmol}, 1.2$ equiv). After the solution was stirred at room temperature for $2.0 \mathrm{~h}$ and then worked up, the residue was purified by use of column chromatography $(10 \% \mathrm{MeOH}$ in dichloromethane as the eluent) to give $\mathbf{7 d}(79.8 \mathrm{mg}, 0.171 \mathrm{mmol})$ in $84 \%$ yield as a white solid: $\mathrm{mp}$ (recrystallized from EtOH) $188.8-189.4{ }^{\circ} \mathrm{C} ;{ }^{1} \mathrm{H}-\mathrm{NMR}$ (DMSO- $\left.d_{6}, 400 \mathrm{MHz}\right) \delta 7.82(\mathrm{~s}$, $1 \mathrm{H}, \mathrm{O}=\mathrm{C}-\mathrm{C}=\mathrm{CH}), 7.72-7.69(\mathrm{~m}, 1 \mathrm{H}, \mathrm{ArH}), 7.60(\mathrm{~s}, 1 \mathrm{H}, \mathrm{ArH}), 7.50(\mathrm{~s}, 1 \mathrm{H}, \mathrm{NCH}), 7.36(\mathrm{~d}, J=8.8 \mathrm{~Hz}, 1 \mathrm{H}$, $\operatorname{ArH}), 7.01(\mathrm{~s}, 1 \mathrm{H}, \mathrm{NCH}), 5.65\left(\mathrm{~d}, J=7.2 \mathrm{~Hz}, 1 \mathrm{H}, \mathrm{H}-1^{\prime \prime}\right), 5.36(\mathrm{~d}, J=6.8 \mathrm{~Hz}, 1 \mathrm{H}, \mathrm{OH}), 5.17(\mathrm{~d}, J=4.4 \mathrm{~Hz}$, $1 \mathrm{H}, \mathrm{OH}), 4.93(\mathrm{t}, J=5.2 \mathrm{~Hz}, 1 \mathrm{H}, \mathrm{OH}), 4.16-4.11\left(\mathrm{~m}, 1 \mathrm{H}, \mathrm{H}-2{ }^{\prime \prime}\right), 4.02\left(\mathrm{~s}, 2 \mathrm{H}, \mathrm{SCH}_{2}\right), 4.00-3.97(\mathrm{~m}, 1 \mathrm{H}$, H-3"), 3.76-3.74 (m, 1H, H-4"), 3.41-3.38 (m, 2H, $\left.2 \times \mathrm{H}-5 "{ }^{\prime \prime}\right) ;{ }^{13} \mathrm{C}-\mathrm{NMR}\left(\mathrm{CDCl}_{3}, 100 \mathrm{MHz}\right) \delta 159.46$ $(\mathrm{C}=\mathrm{O}), 151.95,139.39,139.23,133.82,130.13,129.63,125.68,120.86,119.56,118.25,116.09,88.07,85.56$, 75.02, 70.50, 61.30, $34.33\left(\mathrm{SCH}_{2}\right)$; IR (KBr) 3400 (br, OH), 1693 (s, C=O), 1599 (m), $1479(\mathrm{~m}), 1399$ (m), 1263 (m), 1172 (m) cm ${ }^{-1}$; MS (FAB $\left.{ }^{+}\right) \mathrm{m} / z 469\left(\mathrm{MH}^{+}, 45\right), 154$ (100), 137 (55), 77 (32), 55 (60); HRMS m/z calcd for $\mathrm{C}_{18} \mathrm{H}_{17} \mathrm{~N}_{2} \mathrm{O}_{6} \mathrm{BrS}: 467.9991$, found: 468.0072 .

\subsubsection{1-( $\beta$-D-Ribofuranos-1"'-yl)-2-[(8'-methoxycoumarin-3'-yl)methylthio]imidazole (7e)}

The standard procedure was followed by use of 1- $\beta$-D-ribofuranosyl-imidazole-2-thiol (6, $46.8 \mathrm{mg}, 0.201 \mathrm{mmol}, 1.0$ equiv), aqueous ammonium hydroxide $(0.25 \mathrm{~mL})$, and 3-(chloromethyl)8-methoxycoumarin (2e, $53.8 \mathrm{mg}, 0.241 \mathrm{mmol}, 1.2$ equiv). After the solution was stirred at room temperature for $2.0 \mathrm{~h}$ and then worked up, the residue was purified by use of column chromatography $(10 \% \mathrm{MeOH}$ in dichloromethane as the eluent) to give $7 \mathrm{e}(61.2 \mathrm{mg}, 0.145 \mathrm{mmol})$ in $72 \%$ yield as a white solid: $\mathrm{mp}$ (recrystallized from EtOH) $169.6-170.4{ }^{\circ} \mathrm{C} ;{ }^{1} \mathrm{H}-\mathrm{NMR}$ (DMSO- $\left.d_{6}, 400 \mathrm{MHz}\right) \delta 7.63$ (s, $1 \mathrm{H}, \mathrm{O}=\mathrm{C}-\mathrm{C}=\mathrm{CH}), 7.49(\mathrm{~s}, 1 \mathrm{H}, \mathrm{NCH}), 7.25-7.20(\mathrm{~m}, 2 \mathrm{H}, 2 \times \mathrm{ArH}), 7.10-7.08(\mathrm{~m}, 1 \mathrm{H}, \mathrm{ArH}), 6.99(\mathrm{~s}, 1 \mathrm{H}$, $\mathrm{NCH}), 5.66\left(\mathrm{~d}, J=6.0 \mathrm{~Hz}, 1 \mathrm{H}, \mathrm{H}-1^{\prime \prime}\right), 5.38(\mathrm{~d}, J=6.8 \mathrm{~Hz}, 1 \mathrm{H}, \mathrm{OH}), 5.18(\mathrm{~d}, J=4.4 \mathrm{~Hz}, 1 \mathrm{H}, \mathrm{OH}), 4.94$ $\left.(\mathrm{t}, J=5.2 \mathrm{~Hz}, 1 \mathrm{H}, \mathrm{OH}), 4.16-4.11\left(\mathrm{~m}, 1 \mathrm{H}, \mathrm{H}-2^{\prime \prime}\right), 4.07\left(\mathrm{~s}, 2 \mathrm{H}, \mathrm{SCH}_{2}\right), 4.03-3.97(\mathrm{~m}, 1 \mathrm{H}, \mathrm{H}-3)^{\prime \prime}\right), 3.88(\mathrm{~s}$, $\left.3 \mathrm{H}, \mathrm{OCH}_{3}\right), 3.79-3.76\left(\mathrm{~m}, 1 \mathrm{H}, \mathrm{H}-4^{\prime \prime}\right), 3.43-3.40\left(\mathrm{~m}, 2 \mathrm{H}, 2 \times \mathrm{H}-5^{\prime \prime}\right) ;{ }^{13} \mathrm{C}-\mathrm{NMR}$ (DMSO-d $\left.d_{6}, 100 \mathrm{MHz}\right) \delta$ $159.71(\mathrm{C}=\mathrm{O}), 146.33,142.24,140.85,139.58,129.57,124.60,124.50,119.49,119.36,113.86,88.10,85.54$, 75.05, 70.49, 61.33, $56.08\left(\mathrm{OCH}_{3}\right), 34.14\left(\mathrm{SCH}_{2}\right) ; \mathrm{IR}(\mathrm{KBr}) 3403(\mathrm{br}, \mathrm{OH}), 1695(\mathrm{~s}, \mathrm{C}=\mathrm{O}), 1579(\mathrm{~m}), 1402$ (m), 1265 (m), $1102(\mathrm{~m}), 1078$ (m) cm ${ }^{-1}$; MS (FAB $\left.{ }^{+}\right) \mathrm{m} / z 421\left(\mathrm{MH}^{+}, 15\right), 154$ (100), 137 (30), 77 (66), 55 (67); HRMS $m / z$ calcd for $\mathrm{C}_{19} \mathrm{H}_{20} \mathrm{~N}_{2} \mathrm{O}_{7} \mathrm{~S}: 420.0991$, found: 420.0987 .

\subsubsection{8-[(Coumarin-3'-yl)methylthio]inosine (9a)}

The standard procedure was followed by use of $8(48.7 \mathrm{mg}, 0.162 \mathrm{mmol}, 1.0$ equiv), water $(2.5 \mathrm{~mL})$, acetonitrile $(1.5 \mathrm{~mL})$, aqueous ammonium hydroxide $(0.15 \mathrm{~mL})$, and 3-(chloromethyl) coumarin (2a, $37.8 \mathrm{mg}, 0.194 \mathrm{mmol}, 1.2$ equiv). It was stirred at room temperature for $30 \mathrm{~min}$ and then worked up. The residue was purified by use of column chromatography $\left(10 \%\right.$ methanol in $\mathrm{CH}_{2} \mathrm{Cl}_{2}$ as the eluent) to give $9 \mathbf{a}(52.4 \mathrm{mg}, 0.114 \mathrm{mmol})$ in $70 \%$ yield as a white solid: $\mathrm{mp}$ (recrystallized from dichloromethane/methanol) $160.9-162 .{ }^{\circ} \mathrm{C} ;{ }^{1} \mathrm{H}-\mathrm{NMR}$ (DMSO- $\left.d_{6}, 400 \mathrm{MHz}\right) \delta 8.06$ (s, $\left.1 \mathrm{H}, \mathrm{H}-2\right), 8.02$ (s, $1 \mathrm{H}, \mathrm{CH}=\mathrm{C}-\mathrm{COO}), 7.65-7.57(\mathrm{~m}, 2 \mathrm{H}, 2 \times \mathrm{ArH}), 7.41(\mathrm{~d}, J=8.4 \mathrm{~Hz}, 1 \mathrm{H}, \mathrm{ArH}), 7.33(\mathrm{dd}, J=7.6,7.2 \mathrm{~Hz}, 1 \mathrm{H}$, $\operatorname{ArH}), 5.76\left(\mathrm{~d}, J=6.4 \mathrm{~Hz}, 1 \mathrm{H}, \mathrm{H}-1^{\prime \prime}\right), 5.41(\mathrm{~d}, J=5.6 \mathrm{~Hz}, 1 \mathrm{H}, \mathrm{OH}), 5.19(\mathrm{~d}, J=3.6 \mathrm{~Hz}, 1 \mathrm{H}, \mathrm{OH}), 5.01-4.99$ (br, 1H, OH), 4.89-4.85 (m, 1H, H-2"), 4.39 (d, J = 14.2 Hz, 1H, SCH), $4.35(\mathrm{~d}, J=14.2 \mathrm{~Hz}, 1 \mathrm{H}, \mathrm{SCH})$, 4.12-4.09 (m, 1H, H-3"), 3.88-3.85 (m, 1H, H-4"), 3.63-3.57 (m, 1H, H-5"), 3.50-3.44 (m, 1H, H-5"); ${ }^{13} \mathrm{C}-\mathrm{NMR}$ (DMSO- $\left.d_{6}, 100 \mathrm{MHz}\right) \delta 160.07(\mathrm{C}=\mathrm{O}), 155.37(\mathrm{C}=\mathrm{O}), 152.89,149.57,146.63,145.28,141.20$, 131.76, 128.37, 124.90, 124.60, 123.84, 118.74, 116.10, 88.74, 86.06, 71.16, 70.50, 61.81, $32.04\left(\mathrm{SCH}_{2}\right)$; IR (ATR) 3359 (br, OH + NH), 1707 (s, C=O), 1678 (s, C=O), 1583 (m), 1189 (m), 1051 (s) cm ${ }^{-1}$; MS (FAB ${ }^{+}$) $m / z 459\left(\mathrm{MH}^{+}, 2\right), 327$ (4), 221 (13), 147 (13), 55 (100); HRMS (FAB) calcd for $\left(\mathrm{C}_{20} \mathrm{H}_{18} \mathrm{~N}_{4} \mathrm{O}_{7} \mathrm{~S}+\mathrm{H}\right)^{+}$: 459.0974, found: 459.0984 . 


\subsubsection{8-[(6'-Fluorocoumarin-3'-yl)methylthio]inosine (9b)}

The standard procedure was followed by use of $8(56.7 \mathrm{mg}, 0.189 \mathrm{mmol}, 1.0$ equiv), water $(2.5 \mathrm{~mL})$, acetonitrile $(1.5 \mathrm{~mL})$, aqueous ammonium hydroxide $(0.15 \mathrm{~mL})$, and 3-(chloromethyl)-6-fluorocoumarin ( $2 \mathbf{b}, 48.2 \mathrm{mg}, 0.227 \mathrm{mmol}, 1.2$ equiv). It was stirred at room temperature for $30 \mathrm{~min}$ and then worked up. The residue was purified by use of column chromatography $\left(10 \%\right.$ methanol in $\mathrm{CH}_{2} \mathrm{Cl}_{2}$ as the eluent) to give $9 \mathrm{~b}(74.4 \mathrm{mg}, 0.156 \mathrm{mmol})$ in $83 \%$ yield as a white solid: $\mathrm{mp}$ (recrystallized from dichloromethane/methanol) 168.3-169.1 ${ }^{\circ} \mathrm{C} ;{ }^{1} \mathrm{H}-\mathrm{NMR}$ (DMSO- $\left.d_{6}, 400 \mathrm{MHz}\right) \delta 12.50-12.42$ (br, $1 \mathrm{H}$, $\mathrm{NH}), 8.03(\mathrm{~s}, 1 \mathrm{H}, \mathrm{H}-2), 8.01(\mathrm{~s}, 1 \mathrm{H}, \mathrm{CH}=\mathrm{C}-\mathrm{COO}), 7.56-7.54(\mathrm{~m}, 1 \mathrm{H}, \mathrm{ArH}), 7.48-7.46(\mathrm{~m}, 2 \mathrm{H}, 2 \times \mathrm{ArH})$, $5.76\left(\mathrm{~d}, J=6.4 \mathrm{~Hz}, 1 \mathrm{H}, \mathrm{H}-1^{\prime \prime}\right), 5.43(\mathrm{~d}, J=6.0 \mathrm{~Hz}, 1 \mathrm{H}, \mathrm{OH}), 5.23(\mathrm{~d}, J=4.4 \mathrm{~Hz}, 1 \mathrm{H}, \mathrm{OH}), 5.01-4.99(\mathrm{br}, 1 \mathrm{H}$, $\mathrm{OH}), 4.89-4.85$ (m, 1H, H-2"), 4.39 (d, $J=14.2 \mathrm{~Hz}, 1 \mathrm{H}, \mathrm{SCH}), 4.34(\mathrm{~d}, J=14.2 \mathrm{~Hz}, 1 \mathrm{H}, \mathrm{SCH}), 4.12-4.08$ (m, 1H, H-3"), 3.88-3.84 (m, 1H, H-4"), 3.62-3.57 (m, 1H, H-5"), 3.50-3.44 (m, 1H, H-5"); ${ }^{13} \mathrm{C}-\mathrm{NMR}$ (DMSO- $\left.d_{6}, 100 \mathrm{MHz}\right) \delta 159.86(\mathrm{C}=\mathrm{O}), 158.08(\mathrm{~d}, \mathrm{C}=\mathrm{O}), 155.40,149.60,149.28,146.51,145.35,140.09$, $125.18,124.99,119.75$ (d), 118.95 (d), 118.05 (d), 113.56 (d), 88.79, 86.15, 71.29, 70.45, 61.83, $32.09\left(\mathrm{SCH}_{2}\right)$; IR (ATR) 3359 (br, OH + NH), 1706 (s, C=O), 1676 (s, C=O), 1583 (m), 1452 (m), 1188 (m), 1061 (s) $\mathrm{cm}^{-1}$; MS (FAB $\left.{ }^{+}\right) \mathrm{m} / z 477\left(\mathrm{MH}^{+}, 25\right), 345$ (65), 289 (45), 154 (100), 120 (49); HRMS (FAB) calcd for $\left(\mathrm{C}_{20} \mathrm{H}_{17} \mathrm{FN}_{4} \mathrm{O}_{7} \mathrm{~S}+\mathrm{H}\right)^{+}$: 477.0880, found: 477.0877 .

\subsubsection{8-[(6'-Bromocoumarin-3'-yl)methylthio]inosine (9d)}

The standard procedure was followed by use of 8 ( $45.8 \mathrm{mg}, 0.153 \mathrm{mmol}, 1.0$ equiv), water $(2.5 \mathrm{~mL})$, acetonitrile $(1.5 \mathrm{~mL})$, aqueous ammonium hydroxide $(0.15 \mathrm{~mL})$, and 6-bromo-3-(chloromethyl) coumarin (2d, $50.2 \mathrm{mg}, 0.184 \mathrm{mmol}, 1.2$ equiv). It was stirred at room temperature for $20 \mathrm{~min}$ and then worked up. The residue was purified by use of column chromatography $\left(10 \%\right.$ methanol in $\mathrm{CH}_{2} \mathrm{Cl}_{2}$ as the eluent) to give $9 \mathrm{~d}(66.4 \mathrm{mg}, 0.126 \mathrm{mmol})$ in $80 \%$ yield as a white solid: $\mathrm{mp}$ (recrystallized from dichloromethane/methanol) 169.1-170.5 ${ }^{\circ} \mathrm{C} ;{ }^{1} \mathrm{H}-\mathrm{NMR}$ (DMSO- $\left.d_{6}, 400 \mathrm{MHz}\right) \delta 11.95-11.92(\mathrm{br}, 1 \mathrm{H}$, $\mathrm{NH}), 8.04(\mathrm{~s}, 1 \mathrm{H}, \mathrm{H}-2), 8.00(\mathrm{~s}, 1 \mathrm{H}, \mathrm{CH}=\mathrm{C}-\mathrm{COO}), 7.90(\mathrm{~d}, J=2.4 \mathrm{~Hz}, 1 \mathrm{H}, \mathrm{ArH}), 7.73(\mathrm{dd}, J=8.8,2.4$ $\mathrm{Hz}, 1 \mathrm{H}, \mathrm{ArH}), 7.38$ (d, J = 8.8 Hz, 1H, ArH), 5.76 (d, J = 6.8 Hz, 1H, H-1"), 5.42-5.40 (br, 1H, OH), 5.22-5.20 (br, 1H, OH), 4.96-4.94 (br, 1H, OH), 4.89-4.86 (m, 1H, H-2"), 4.38 (d, J = 14.4 Hz, 1H, SCH), $4.34(\mathrm{~d}, J=14.4 \mathrm{~Hz}, 1 \mathrm{H}, \mathrm{SCH}), 4.12-4.09$ (m, 1H, H-3"), 3.88-3.85 (m, 1H, H-4"), 3.62-3.59 (m, 1H, H-5"), 3.50-3.45 (m, 1H, H-5"); ${ }^{13} \mathrm{C}-\mathrm{NMR}$ (DMSO- $\left.d_{6}, 100 \mathrm{MHz}\right) \delta 159.61$ (C=O), 155.36 (C=O), 151.93, 149.58, $146.45,145.32,139.72,134.08,130.32,125.19,124.98,120.66,118.36,116.21,88.79,86.15,71.29,70.45$, 61.83, $32.09\left(\mathrm{SCH}_{2}\right)$; IR (ATR) $3356(\mathrm{br}, \mathrm{OH}+\mathrm{NH}), 1708(\mathrm{~s}, \mathrm{C}=\mathrm{O}), 1678(\mathrm{~s}, \mathrm{C}=\mathrm{O}), 1585(\mathrm{~m}), 1188(\mathrm{~m})$, $1022(\mathrm{~s}) \mathrm{cm}^{-1}$; MS (FAB $\left.{ }^{+}\right) \mathrm{m} / z 537\left(\mathrm{MH}^{+}, 2\right), 427$ (13), 307 (19), 185 (26), 154 (100); HRMS (FAB) calcd for $\left(\mathrm{C}_{20} \mathrm{H}_{17} \mathrm{BrN}_{4} \mathrm{O}_{7} \mathrm{~S}+\mathrm{H}\right)^{+}$: 537.0080, found: 537.0077 .

\subsubsection{8-[(8'-Methoxycoumarin-3'-yl)methylthio]inosine (9e)}

The standard procedure was followed by use of $8(35.8 \mathrm{mg}, 0.119 \mathrm{mmol}, 1.0$ equiv), water $(2.5 \mathrm{~mL})$, acetonitrile $(1.5 \mathrm{~mL})$, aqueous ammonium hydroxide $(0.15 \mathrm{~mL})$, and 3-chloromethyl8-methoxycoumarin (2e, $41.9 \mathrm{mg}, 0.201 \mathrm{mmol}, 1.2$ equiv). It was stirred at room temperature for $30 \mathrm{~min}$ and then worked up. The residue was purified by use of column chromatography $(10 \%$ methanol in $\mathrm{CH}_{2} \mathrm{Cl}_{2}$ as the eluent) to give $9 \mathrm{e}(46.7 \mathrm{mg}$, $95.6 \mu \mathrm{mol})$ in $80 \%$ yield as a white solid: $\mathrm{mp}$ (recrystallized from dichloromethane/methanol) $162.3-164.1^{\circ} \mathrm{C} ;{ }^{1} \mathrm{H}-\mathrm{NMR}$ (DMSO- $\left.d_{6}, 400 \mathrm{MHz}\right) \delta$ 12.52-12.39 (br, 1H, NH), 8.04 (s, 1H, H-2), 8.03 (s, 1H, CH=C-COO), 7.28-7.23 (m, 2H, $2 \times \mathrm{ArH})$, 7.18-7.16 (m, 1H, ArH), 5.75 (d, J = 6.4 Hz, 1H, H-1"), 5.45-5.41 (br, 1H, OH), 5.23-5.21 (br, 1H, OH), $4.96(\mathrm{dd}, J=6.0,5.6 \mathrm{~Hz}, 1 \mathrm{H}, \mathrm{OH}), 4.88-4.85\left(\mathrm{~m}, 1 \mathrm{H}, \mathrm{H}-2^{\prime \prime}\right), 4.39(\mathrm{~d}, J=14.0 \mathrm{~Hz}, 1 \mathrm{H}, \mathrm{SCH}), 4.34(\mathrm{~d}$, $J=14.0 \mathrm{~Hz}, 1 \mathrm{H}, \mathrm{SCH}), 4.13-4.09\left(\mathrm{~m}, 1 \mathrm{H}, \mathrm{H}-3{ }^{\prime \prime}\right), 3.89\left(\mathrm{~s}, 3 \mathrm{H}, \mathrm{OCH}_{3}\right), 3.87-3.85\left(\mathrm{~m}, 1 \mathrm{H}, \mathrm{H}-4^{\prime \prime}\right), 3.62-3.59$ (m, 1H, H-5"), 3.49-3.46 (m, 1H, H-5"); ${ }^{13} \mathrm{C}-\mathrm{NMR}$ (DMSO- $\left.d_{6}, 100 \mathrm{MHz}\right) \delta 159.83(\mathrm{C}=\mathrm{O}), 155.39$ (C=O), 149.60, 146.69, 146.39, 145.31, 142.24, 141.15, 124.96, 124.67, 124.03, 119.49, 119.32, 114.13, 88.76, 86.15, 71.28, 70.46, 61.83, $56.10\left(\mathrm{OCH}_{3}\right), 32.01\left(\mathrm{SCH}_{2}\right)$; IR (ATR) 3354 (br, OH + NH), 1708 (s, C=O), $1692(\mathrm{~s}$, 
$\mathrm{C}=\mathrm{O}), 1583(\mathrm{~m}), 1189(\mathrm{~m}), 1060$ (s) $\mathrm{cm}^{-1}$; MS (ESI) $\mathrm{m} / z 488\left(\mathrm{M}^{+}\right)$; HRMS (ESI) calcd for $\left(\mathrm{C}_{21} \mathrm{H}_{20} \mathrm{~N}_{4} \mathrm{O}_{8} \mathrm{~S}\right)^{+}$: 488.1002, found: 488.1011 .

\subsubsection{8-[(6'-Methylcoumarin-3'-yl)methylthio]inosine (9f)}

The standard procedure was followed by use of 8 ( $50.2 \mathrm{mg}, 0.167 \mathrm{mmol}, 1.0$ equiv), water ( $2.5 \mathrm{~mL})$, acetonitrile $(1.5 \mathrm{~mL})$, aqueous ammonium hydroxide $(0.15 \mathrm{~mL})$, and 3-chloromethyl-6-methylcoumarin (2f, $41.9 \mathrm{mg}, 0.201 \mathrm{mmol}, 1.2$ equiv). It was stirred at room temperature for $15 \mathrm{~min}$ and then worked up. The residue was purified by use of column chromatography $\left(10 \%\right.$ methanol in $\mathrm{CH}_{2} \mathrm{Cl}_{2}$ as the eluent) to give 9f $(64.6 \mathrm{mg}, 0.137 \mathrm{mmol})$ in $82 \%$ yield as a white solid: $\mathrm{mp}$ (recrystallized from dichloromethane/methanol) $156.8-158.4{ }^{\circ} \mathrm{C} ;{ }^{1} \mathrm{H}-\mathrm{NMR}$ (DMSO- $\left.d_{6}, 400 \mathrm{MHz}\right) \delta 12.48-12.38$ (br, $1 \mathrm{H}$, $\mathrm{NH}), 8.03(\mathrm{~s}, 1 \mathrm{H}, \mathrm{H}-2), 8.01(\mathrm{~s}, 1 \mathrm{H}, \mathrm{CH}=\mathrm{C}-\mathrm{COO}), 7.41-7.38(\mathrm{~m}, 2 \mathrm{H}, 2 \times \mathrm{ArH}), 7.30(\mathrm{~d}, J=8.4 \mathrm{~Hz}, 1 \mathrm{H}$, $\operatorname{ArH}), 5.75\left(\mathrm{~d}, J=6.4 \mathrm{~Hz}, 1 \mathrm{H}, \mathrm{H}-1^{\prime \prime}\right), 5.43(\mathrm{~d}, J=5.2 \mathrm{~Hz}, 1 \mathrm{H}, \mathrm{OH}), 5.22(\mathrm{~d}, J=2.4 \mathrm{~Hz}, 1 \mathrm{H}, \mathrm{OH}), 4.95(\mathrm{dd}$, $J=6.0,5.6 \mathrm{~Hz}, 1 \mathrm{H}, \mathrm{OH}), 4.88-4.86\left(\mathrm{~m}, 1 \mathrm{H}, \mathrm{H}-2^{\prime \prime}\right), 4.38(\mathrm{~d}, J=14.0 \mathrm{~Hz}, 1 \mathrm{H}, \mathrm{SCH}), 4.34(\mathrm{~d}, J=14.0 \mathrm{~Hz}$, $1 \mathrm{H}, \mathrm{SCH}), 4.12-4.09$ (m, 1H, H-3"), 3.89-3.85 (m, 1H, H-4"), 3.64-3.58 (m, 1H, H-5"), 3.51-3.48 (m, 1H, H-5"), 2.32 (s, 3H, $\left.\mathrm{CH}_{3}\right) ;{ }^{13} \mathrm{C}-\mathrm{NMR}$ (DMSO- $\left.d_{6}, 100 \mathrm{MHz}\right) \delta 160.26$ (C=O), 155.37 (C=O), 151.07, 149.62, 146.77, 145.27, 141.16, 134.00, 132.66, 127.95, 124.95, 123.78, 118.50, 115.86, 88.76, 86.15, 71.29, 70.45, 61.85, $32.00\left(\mathrm{SCH}_{2}\right), 20.17\left(\mathrm{CH}_{3}\right)$; IR (ATR) $3345(\mathrm{br}, \mathrm{OH}+\mathrm{NH}), 1707$ (s, C=O), 1692 (s, C=O), $1583(\mathrm{~m})$, 1188 (m), 1023 (s) cm ${ }^{-1}$; MS (FAB $\left.{ }^{+}\right) \mathrm{m} / z 473\left(\mathrm{MH}^{+}, 1\right), 341$ (10), 185 (16), 109 (30), 55 (100); HRMS (FAB) calcd for $\left(\mathrm{C}_{21} \mathrm{H}_{20} \mathrm{~N}_{4} \mathrm{O}_{7} \mathrm{~S}\right)^{+}: 472.1053$, found: 472.1060 .

\subsubsection{8-[(6'-Fluorocoumarin-3'-yl)methylthio]guanosine (11b)}

The standard procedure was followed by use of $10(65.2 \mathrm{mg}, 0.207 \mathrm{mmol}, 1.0$ equiv), water $(5.0 \mathrm{~mL})$, acetonitrile $(3.0 \mathrm{~mL})$, aqueous ammonium hydroxide $(0.25 \mathrm{~mL})$, and 3-chloromethyl-6-fluorocoumarin (2b, $52.8 \mathrm{mg}, 0.248 \mathrm{mmol}, 1.2$ equiv). It was stirred at room temperature for $15 \mathrm{~min}$ and then worked up. The residue was purified by use of column chromatography (15\% methanol in $\mathrm{CH}_{2} \mathrm{Cl}_{2}$ as the eluent) to give $11 \mathrm{~b}(90.2 \mathrm{mg}, 0.183 \mathrm{mmol})$ in $89 \%$ yield as a white solid: $\mathrm{mp}$ (recrystallized from dichloromethane/methanol) 184.9-186.2 ${ }^{\circ} \mathrm{C} ;{ }^{1} \mathrm{H}-\mathrm{NMR}$ (DMSO- $\left.d_{6}, 400 \mathrm{MHz}\right) \delta 10.70-10.66$ (br, $1 \mathrm{H}$, $\mathrm{NH}), 7.90(\mathrm{~s}, 1 \mathrm{H}, \mathrm{CH}=\mathrm{C}-\mathrm{COO}), 7.53-7.42(\mathrm{~m}, 3 \mathrm{H}, 3 \times \mathrm{ArH}), 6.41\left(\mathrm{~s}, 2 \mathrm{H}, \mathrm{NH}_{2}\right), 5.70(\mathrm{~d}, J=6.8 \mathrm{~Hz}, 1 \mathrm{H}$, $\left.\mathrm{H}-1{ }^{\prime \prime}\right), 5.35(\mathrm{~d}, J=6.0 \mathrm{~Hz}, 1 \mathrm{H}, \mathrm{OH}), 5.07(\mathrm{~d}, J=4.8 \mathrm{~Hz}, 1 \mathrm{H}, \mathrm{OH}), 4.94(\mathrm{dd}, J=6.8,5.2 \mathrm{~Hz}, 1 \mathrm{H}, \mathrm{OH})$, 4.89-4.85 (m, 1H, H-2"), 4.24 (d, J = 14.0 Hz, 1H, SCH), 4.19 (d, J = 14.0 Hz, 1H, SCH), 4.10-4.06 (m, 1H, H-3"), 3.80-3.76 (m, 1H, H-4"), 3.62-3.56 (m, 1H, H-5"), 3.49-3.43 (m, 1H, H-5"); ${ }^{13} \mathrm{C}-\mathrm{NMR}$ (DMSO- $d_{6}$, $100 \mathrm{MHz}) \delta 159.83(\mathrm{C}=\mathrm{O}), 158.07$ (d, C=O), 155.60, 153.10, 152.47, 149.25, 141.48, 139.84, 125.44, 119.81 (d), 118.83 (d), 118.00 (d), 117.42, 113.47 (d), 88.27, 85.74, 70.53, 61.96, $32.77\left(\mathrm{SCH}_{2}\right)$; IR (ATR) 3146 (br, $\mathrm{OH}+\mathrm{NH}), 1723(\mathrm{~m}, \mathrm{C}=\mathrm{O}), 1681(\mathrm{~s}, \mathrm{C}=\mathrm{O}), 1626(\mathrm{~s}), 1071(\mathrm{~s}) \mathrm{cm}^{-1} ; \mathrm{MS}\left(\mathrm{FAB}^{+}\right) \mathrm{m} / \mathrm{z} 492\left(\mathrm{MH}^{+}, 35\right), 360$ (62), 307 (98), 219 (23), 156 (100), 107 (100); HRMS (FAB) calcd for $\left(\mathrm{C}_{20} \mathrm{H}_{18} \mathrm{FN}_{5} \mathrm{O}_{7} \mathrm{~S}+\mathrm{H}\right)^{+}$: 492.0989, found: 492.0996.

\subsubsection{8-[(8'-Methoxycoumarin-3'-yl)methylthio]guanosine (11e)}

The standard procedure was followed by use of $10(63.7 \mathrm{mg}, 0.202 \mathrm{mmol}, 1.0$ equiv), water $(5.0 \mathrm{~mL})$, acetonitrile $(3.0 \mathrm{~mL})$, aqueous ammonium hydroxide $(0.25 \mathrm{~mL})$, and 3-chloromethyl-8methoxycoumarin (2e, $54.0 \mathrm{mg}, 0.243 \mathrm{mmol}, 1.2$ equiv). It was stirred at room temperature for $1.0 \mathrm{~h}$ and then worked up. The residue was purified by use of column chromatography ( $10 \%$ methanol in $\mathrm{CH}_{2} \mathrm{Cl}_{2}$ as the eluent) to give $11 \mathrm{e}(84.3 \mathrm{mg}, 0.167 \mathrm{mmol}$ ) in $83 \%$ yield as a white solid: $\mathrm{mp}$ (recrystallized from dichloromethane/methanol) $192.8-194.3^{\circ} \mathrm{C} ;{ }^{1} \mathrm{H}-\mathrm{NMR}$ (DMSO- $\left.d_{6}, 400 \mathrm{MHz}\right) \delta 10.68-10.64$ (br, $1 \mathrm{H}, \mathrm{NH}), 7.93(\mathrm{~s}, 1 \mathrm{H}, \mathrm{CH}=\mathrm{C}-\mathrm{COO}), 7.28-7.23(\mathrm{~m}, 2 \mathrm{H}, 2 \times \mathrm{ArH}), 7.16-7.14(\mathrm{~m}, 1 \mathrm{H}, \mathrm{ArH}), 6.42(\mathrm{~s}, 2 \mathrm{H}$, $\left.\mathrm{NH}_{2}\right), 5.69\left(\mathrm{~d}, J=6.8 \mathrm{~Hz}, 1 \mathrm{H}, \mathrm{H}-1^{\prime \prime}\right), 5.38(\mathrm{~d}, J=6.4 \mathrm{~Hz}, 1 \mathrm{H}, \mathrm{OH}), 5.09(\mathrm{~d}, J=5.2 \mathrm{~Hz}, 1 \mathrm{H}, \mathrm{OH}), 4.95(\mathrm{dd}$, $J=6.0,5.6 \mathrm{~Hz}, 1 \mathrm{H}, \mathrm{OH}), 4.88-4.84\left(\mathrm{~m}, 1 \mathrm{H}, \mathrm{H}-2^{\prime \prime}\right), 4.24(\mathrm{~d}, J=13.8 \mathrm{~Hz}, 1 \mathrm{H}, \mathrm{SCH}), 4.19(\mathrm{~d}, J=13.8 \mathrm{~Hz}, 1 \mathrm{H}$, $\mathrm{SCH}), 4.09-4.05\left(\mathrm{~m}, 1 \mathrm{H}, \mathrm{H}-3{ }^{\prime \prime}\right), 3.89\left(\mathrm{~s}, 3 \mathrm{H}, \mathrm{OCH}_{3}\right), 3.80-3.77$ (m, 1H, H-4"), 3.61-3.56 (m, 1H, H-5"), 3.49-3.43 (m, 1H, H-5"); ${ }^{13} \mathrm{C}-\mathrm{NMR}$ (DMSO- $\left.d_{6}, 100 \mathrm{MHz}\right) \delta 159.87$ (C=O), 155.68 (C=O), 153.14, 152.55, $146.41,142.25,141.73,141.24,124.66,124.34,119.47,119.41,117.38,114.05,88.26,85.78,70.53,62.01$, 
$56.16\left(\mathrm{OCH}_{3}\right), 32.63\left(\mathrm{SCH}_{2}\right)$; IR (ATR) $3142(\mathrm{br}, \mathrm{OH}+\mathrm{NH}), 1714(\mathrm{~m}, \mathrm{C}=\mathrm{O}), 1682(\mathrm{~s}, \mathrm{C}=\mathrm{O}), 1274(\mathrm{~m})$, $1092(\mathrm{~m}) \mathrm{cm}^{-1}$; MS (FAB $\left.{ }^{+}\right) \mathrm{m} / z 503\left(\mathrm{M}^{+}, 2\right), 372$ (10), 232 (11), 154 (45), 79 (100); HRMS (FAB) calcd for $\left(\mathrm{C}_{21} \mathrm{H}_{21} \mathrm{~N}_{5} \mathrm{O}_{8} \mathrm{~S}\right)^{+}:$503.1107, found: 503.1111.

\subsubsection{8-[(6'-Methylcoumarin-3'-yl)methylthio]guanosine (11f)}

The standard procedure was followed by use of $\mathbf{1 0}(52.3 \mathrm{mg}, 0.166 \mathrm{mmol}, 1.0$ equiv), water $(5.0 \mathrm{~mL})$, acetonitrile $(3.0 \mathrm{~mL})$, aqueous ammonium hydroxide $(0.25 \mathrm{~mL})$, and 3-chloromethyl-6-methylcoumarin (2f, $41.5 \mathrm{mg}, 0.199 \mathrm{mmol}, 1.2$ equiv). It was stirred at room temperature for $30 \mathrm{~min}$ and then worked up. The residue was purified by use of column chromatography (15\% methanol in $\mathrm{CH}_{2} \mathrm{Cl}_{2}$ as the eluent) to give $11 \mathrm{f}(59.6 \mathrm{mg}, 0.122 \mathrm{mmol})$ in $74 \%$ yield as a white solid: ${ }^{1} \mathrm{H}-\mathrm{NMR}$ (DMSO- $\left.d_{6}, 400 \mathrm{MHz}\right)$ $\delta$ 10.74-10.70 (br, 1H, NH), 7.90 (s, 1H, CH=C-COO), 7.40-7.38 (m, 2H, $2 \times \mathrm{ArH}), 7.30(\mathrm{~d}, J=8.8 \mathrm{~Hz}$, $1 \mathrm{H}, \mathrm{ArH}), 6.46\left(\mathrm{~s}, 2 \mathrm{H}, \mathrm{NH}_{2}\right), 5.69\left(\mathrm{~d}, J=6.4 \mathrm{~Hz}, 1 \mathrm{H}, \mathrm{H}-1^{\prime \prime}\right), 5.38(\mathrm{~d}, J=6.4 \mathrm{~Hz}, 1 \mathrm{H}, \mathrm{OH}), 5.09$ (d, $J=4.8 \mathrm{~Hz}, 1 \mathrm{H}, \mathrm{OH}), 4.95(\mathrm{dd}, J=6.0,6.0 \mathrm{~Hz}, 1 \mathrm{H}, \mathrm{OH}), 4.88-4.84\left(\mathrm{~m}, 1 \mathrm{H}, \mathrm{H}-2^{\prime \prime}\right), 4.24(\mathrm{~d}, J=13.8 \mathrm{~Hz}, 1 \mathrm{H}$, $\mathrm{SCH}), 4.19$ (d, $J=13.8 \mathrm{~Hz}, 1 \mathrm{H}, \mathrm{SCH}), 4.11-4.06$ (m, 1H, H-3"), 3.81-3.78 (m, 1H, H-4"), 3.63-3.57 (m, 1H, H-5"), 3.50-3.43 (m, 1H, H-5"), 2.33 (s, 3H, CH $)^{\prime}$; ${ }^{3} \mathrm{C}-\mathrm{NMR}$ (DMSO-d, $\left.100 \mathrm{MHz}\right) \delta 160.31$ (C=O), $155.64(\mathrm{C}=\mathrm{O}), 153.25,152.53,151.08,141.71,140.95,134.00,132.61,127.96,124.08,118.61,117.38,115.87$, 88.29, 85.77, 70.60, 62.03, $32.65\left(\mathrm{SCH}_{2}\right), 20.23\left(\mathrm{CH}_{3}\right)$; IR (ATR) 3301 (br, OH + NH), $1720(\mathrm{~m}, \mathrm{C}=\mathrm{O}), 1644$ (s, C=O), 1566 (m), 1081 (s) cm ${ }^{-1}$; MS (FAB $\left.{ }^{+}\right) m / z 487\left(\mathrm{M}^{+}, 1\right), 185$ (9), 97 (31), 55 (100); HRMS (FAB) calcd for $\left(\mathrm{C}_{21} \mathrm{H}_{21} \mathrm{~N}_{5} \mathrm{O}_{7} \mathrm{~S}\right)^{+}:$487.1162, found: 487.1162 .

\section{Conclusions}

Four new compound sets containing 20 imidazole-coumarin conjugates were established. Experimental results indicate that five among the 20 conjugates significantly inhibited HCV subgenomic replicon replication in the Huh 5-2 cell lines. In particular, the series of $1 H$-imidazole conjugates (i.e., $\mathbf{3 b}, \mathbf{3 d}$, and $\mathbf{3 e}$ ) exhibited the most appealing results, with $\mathrm{EC}_{50}$ values of 7.2, 5.1, and $8.4 \mu \mathrm{M}$ together with SI values of 12,15 , and 21 , respectively. The imidazole ring can be $N$-alkylated or ribosylated as well as replaced by a benzimidazole, inosine, or guanosine. Nevertheless, the parent imidazole conjugates with an $\mathrm{N}-\mathrm{H}$ proton generally offers a higher SI value than those without such a proton. Moreover, incorporation of substituents into the coumarin rings can increase both potency and selectivity of the conjugates. These guidelines provide a valuable reference for medicinal scientists attempting to optimize the anti-viral compounds during the drug development stage. The mechanism of action of these conjugated compounds with significant activity towards viral enzymes will be studies in due course.

Supplementary Materials: Supplementary materials can be accessed at: http:/ /www.mdpi.com/1420-3049/21/ 2/228/s1.

Acknowledgments: For financial support, we thank Ministry of Science and Technology of R.O.C. (grant No. NSC 102-2633-M-007-001 and MOST 103-2113-M-007-018-MY3), Ministry of Education of R.O.C. (grant No. 104N2011E1 and 104N2016E1), and National Central University (grant No. 103G603-14). The work in Leuven is supported by the European Commission SILVER project within the 7th Framework Program as Cooperation Project Grant Agreement (No. 260644).

Author Contributions: S.-C. Tsay and J.R. Hwu-initiation of the project, design of the compounds, writing of the paper. S.-Y. Lin, W.-C. Huang, and M.-H. Hsu—synthesis and analysis/characterization of the compounds. K. C. Hwang, C.-C. Lin, J.-C. Horng, I-C. Chen, and F.-K. Shieh-interpretation of SAR results, providing the concepts of the works. P. Leyssen — study of anti-HCV activity. J. Neyts-pharmacology evaluation, preparation of the paper.

Conflicts of Interest: The authors declare no conflict of interest.

\section{References}

1. Murphy, D.G.; Sablon, E.; Chamberland, J.; Fournier, E.; Dandavino, R.; Tremblay, C.L. Hepatitis C virus genotype 7, a new genotype originating from central Africa. J. Clin. Microbiol. 2015, 53, 967-972. [CrossRef] [PubMed] 
2. Oze, T.; Hiramatsu, N.; Mita, E.; Akuta, N.; Sakamoto, N.; Nagano, H.; Itoh, Y.; Kaneko, S.; Izumi, N.; Nomura, H.; et al. A multicenter survey of re-treatment with pegylated interferon plus ribavirin combination therapy for patients with chronic hepatitis C in Japan. Hepatol. Res. 2013, 43, 35-43. [CrossRef] [PubMed]

3. Kwong, A.D.; Kauffman, R.S.; Hurter, P.; Mueller, P. Discovery and development of telaprevir: An NS3-4A protease inhibitor for treating genotype 1 chronic hepatitis C virus. Nat. Biotechnol. 2011, 29, 993-1003. [CrossRef] [PubMed]

4. Thibault, P.A.; Wilson, J.A. Targeting miRNAs to treat hepatitis $C$ virus infections and liver pathology: Inhibiting the virus and altering the host. Pharmacol. Res. 2013, 75, 48-59. [CrossRef] [PubMed]

5. Hulskotte, E.G.J.; Feng, H.-P.; Xuan, F.; Gupta, S.; van Zutven, M.G.J.A.; O'Mara, E.; Wagner, J.A.; Butterton, J.R. Pharmacokinetic evaluation of the interaction between hepatitis $C$ virus protease inhibitor boceprevir and 3-hydroxy-3-methylglutaryl coenzyme A reductase inhibitors atorvastatin and pravastatin. Antimicrob. Agents Chemother. 2013, 57, 2582-2588. [CrossRef] [PubMed]

6. Orrin, E.; Barnabas, A.; Agarwal, K.; Walsh, S.A. Cutaneous side-effects of antihepatitis C treatment: The U.K. experience. Br. J. Dermatol. 2015, 172, 292-293. [CrossRef] [PubMed]

7. U.S. Food and Drug Administration. FDA Approves First Combination Pill to Treat Hepatitis C. Available online: http://www.fda.gov/NewsEvents/Newsroom/PressAnnouncements/ucm418365.htm (accessed on 10 October 2014).

8. U.S. Food and Drug Administration. FDA Approves Viekira Pak to Treat Hepatitis C. Available online: http://www.fda.gov/NewsEvents/Newsroom/PressAnnouncements/ucm427530.htm (accessed on 19 December 2014).

9. Van de Ven, N.; Fortunak, J.; Simmons, B.; Ford, N.; Cooke, G.S.; Khoo, S.; Hill, A. Minimum target prices for production of direct-acting antivirals and associated diagnostics to combat hepatitis $\mathrm{C}$ virus. Hepatology 2015, 61, 1174-1182. [CrossRef] [PubMed]

10. Tsay, S.-C.; Hwu, J.R.; Singha, R.; Huang, W.-C.; Chang, Y.H.; Hsu, M.-H.; Shieh, F.-K.; Lin, C.-C.; Hwang, K.C.; Horng, J.-C.; et al. Coumarins hinged directly on benzimidazoles and their ribofuranosides to inhibit hepatitis C virus. Eur. J. Med. Chem. 2013, 63, 290-298. [CrossRef] [PubMed]

11. Hwu, J.R.; Singha, R.; Hong, S.-C.; Chang, Y.-H.; Das, A.R.; Vliegen, I.; de Clercq, E.; Neyts, J. Synthesis of new benzimidazole-coumarin conjugates as anti-hepatitis C virus agents. Antivir. Res. 2008, 77, 152-162. [CrossRef] [PubMed]

12. Neyts, J.; de Clercq, E.; Singha, R.; Chang, Y.-H.; Das, A.R.; Chakraborty, S.K.; Hong, S.-C.; Tsay, S.-C.; Hsu, M.-H.; Hwu, J.R. Structure-activity relationship of new anti-hepatitis C virus agents: Heterobicycle-coumarin conjugates. J. Med. Chem. 2009, 52, 1486-1490. [CrossRef] [PubMed]

13. Hwu, J.R.; Lin, S.-Y.; Tsay, S.-C.; de Clercq, E.; Leyssen, P.; Neyts, J. Coumarin-purine ribofuranoside conjugates as new agents against hepatitis C virus. J. Med. Chem. 2011, 54, 2114-2126. [CrossRef] [PubMed]

14. Hwu, J.R.; Lin, S.-Y.; Tsay, S.-C.; Singha, R.; Pal, B.K.; Leyssen, P.; Neyts, J. Development of New Sulfur-Containing Conjugated Compounds as Anti-HCV Agents. Phosphorus Sulfur Silicon Relat. Elem. 2011, 186, 1144-1152. [CrossRef]

15. Nichols, D.B.; Leão, R.A.; Basu, A.; Chudayeu, M.; de Moraes, P.F.; Talele, T.T.; Costa, P.R.; Kaushik-Basu, N. Evaluation of coumarin and neoflavone derivatives as HCV NS5B polymerase inhibitors. Chem. Biol. Drug Des. 2013, 81, 607-614. [CrossRef] [PubMed]

16. Cervi, A.; Aillard, P.; Hazeri, N.; Petit, L.; Chai, C.L.L.; Willis, A.C.; Banwell, M.G. Total syntheses of the coumarin-containing natural products pimpinellin and fraxetin using $\mathrm{Au}(\mathrm{I})$-catalyzed intramolecular hydroarylation (IMHA) chemistry. J. Org. Chem. 2013, 78, 9876-9882. [CrossRef] [PubMed]

17. François, J.; Raymond, A. Small-Molecule Hepatitis C Virus (HCV) ns3/4a Serine Protease Inhibitors. WO Patent 128344 A1, 30 October 2008.

18. Njoroge, F.G.; Chen, K.X.; Shih, N.-Y.; Piwinski, J.J. Challenges in modern drug discovery: A case study of boceprevir, an $\mathrm{HCV}$ protease inhibitor for the treatment of hepatitis $\mathrm{C}$ virus infection. Acc. Chem. Res. 2008, 41, 50-59. [CrossRef] [PubMed]

19. Lin, C.; Kwong, A.D.; Perni, R.B. Discovery and development of VX-950, a novel, covalent, and reversible inhibitor of hepatitis C virus NS3.4A serine protease. Infect. Disord. Drug Targets 2006, 6, 3-16. [CrossRef] [PubMed] 
20. Khabnadideh, S.; Rezaei, Z.; Khalafi-Nezhad, A.; Bahrinajafi, R.; Mohamadi, R.; Farrokhroz, A.A. Synthesis of $\mathrm{N}$-alkylated derivatives of imidazole as antibacterial agents. Bioorg. Med. Chem. Lett. 2003, 13, 2863-2865. [CrossRef]

21. Bhatnagar, A.; Sharma, P.K.; Kumar, N. A review on "imidazoles": Their chemistry and pharmacological potentials. Int. J. Pharmtech Res. 2011, 3, 268-282.

22. Chen, J.; Wang, Z.; Li, C.M.; Lu, Y.; Vaddady, P.K.; Meibohm, B.; Dalton, J.T.; Miller, D.D.; Li, W. Discovery of novel 2-aryl-4-benzoyl-imidazoles targeting the colchicines binding site in tubulin as potential anticancer agents. J. Med. Chem. 2010, 53, 7414-7427. [CrossRef] [PubMed]

23. Sharma, D.; Narasimhan, B.; Kumar, P.; Judge, V.; Narang, R.; de Clercq, E.; Balzarini, J. Synthesis, antimicrobial and antiviral evaluation of substituted imidazole derivatives. Eur. J. Med. Chem. 2009, 44, 2347-2353. [CrossRef] [PubMed]

24. Lagoja, I.M.; Pannecouque, C.; van Aerschot, A.; Witvrouw, M.; Debyser, Z.; Balzarini, J.; Herdewijn, P.; de Clercq, E. N-Aminoimidazole derivatives inhibiting retroviral replication via a yet unidentified mode of action. J. Med. Chem. 2003, 46, 1546-1553. [CrossRef] [PubMed]

25. Scheiner, S.; Yi, M. The proton transfer properties of imidazole. J. Phys. Chem. 1996, 100, 9235-9241. [CrossRef]

26. Chen, J.; Li, C.-M.; Wang, J.; Ahn, S.; Wang, Z.; Lu, Y.; Dalton, J.T.; Miller, D.D.; Li, W. Synthesis and antiproliferative activity of novel 2-aryl-4-benzoyl-imidazole derivatives targeting tubulin polymerization. Bioorg. Med. Chem. 2011, 19, 4782-4795. [CrossRef] [PubMed]

27. Fasciano, J.; Steele, T.; Castagnoli, N.; Katz, J.; Ricaurte, G. The effect of N-methylation on fenfluramine's neurotoxic and pharmacologic actions. Brain Res. 1997, 763, 182-190. [CrossRef]

28. Zai, L.; Ferrari, C.; Subbaiah, S.; Havton, L.A.; Coppola, G.; Strittmatter, S.; Irwin, N.; Geschwind, D.; Benowitz, L.I. Inosine alters gene expression and axonal projections in neurons contralateral to a cortical infarct and improves skilled use of the impaired limb. J. Neurosci. 2009, 29, 8187-8197. [CrossRef] [PubMed]

29. Liaudet, L.; Mabley, J.G.; Pacher, P.; Virag, L.; Soriano, F.G.; Marton, A.; Haskó, G.; Deitch, E.A.; Szabó, C. Inosine exerts a broad range of anti-inflammatory effects in a murine model of acute lung injury. Ann. Surg. 2002, 235, 568-578. [CrossRef] [PubMed]

30. Cianciara, J.; Laskus, T.; Gabinska, E.; Loch, T. Isoprinosine in the treatment of chronic active hepatitis type B. Scand. J. Infect. Dis. 1990, 22, 645-648. [CrossRef] [PubMed]

31. Kowalik-Mikołajewska, B. Course of chronic virus hepatitis B in children and attempts at modifying its treatment. Pol. Tyg. Lek. 1993, 48, 258-260. [PubMed]

32. Njei, B.; Garg, S.K.; Kenta-Bibi, E.; Kongnyuy, E.J.; Alam, S.E. Isoprinosine for chronic hepatitis B. Cochrane Database Syst. Rev. 2014. [CrossRef]

33. Giuliani, P.; Romano, S.; Ballerini, P.; Ciccarelli, R.; Petragnani, N.; Cicchitti, S.; Zuccarini, M.; Jiang, S.; Rathbone, M.P.; Caciagli, F.; et al. Protective activity of guanosine in an in vitro model of Parkinson's disease. Panminerva Med. 2012, 54, 43-51. [PubMed]

34. Sizun, G.; Pierra, C.; Peyronnet, J.; Badaroux, E.; Rabeson, C.; Benzaria-Prad, S.; Surleraux, D.; Loi, A.G.; Musiu, C.; Liuzzi, M.; et al. Design, synthesis and antiviral evaluation of 2'-C-methyl branched guanosine pronucleotides: The discovery of IDX184, a potent liver-targeted HCV polymerase inhibitor. Future Med. Chem. 2015, 7, 1675-1700. [CrossRef] [PubMed]

35. Ali-von Laue, C.; Zoschke, C.; Do, N.; Lehnen, D.; Küchler, S.; Mehnert, W.; Blaschke, T.; Kramer, K.D.; Plendl, J.; Weindl, G.; et al. Improving topical non-melanoma skin cancer treatment: In vitro efficacy of a novel guanosine-analog phosphonate. Skin Pharmacol. Physiol. 2014, 27, 173-180. [CrossRef] [PubMed]

36. Simons, C.; Wu, Q.; Htar, T.T. Recent advances in antiviral nucleoside and nucleotide therapeutics. Curr. Top. Med. Chem. 2005, 5, 1191-1203. [CrossRef] [PubMed]

37. Chien, T.C.; Saluja, S.S.; Drach, J.C.; Townsend, L.B. Synthesis and antiviral evaluation of polyhalogenated imidazole nucleosides: Dimensional analogues of 2,5,6-trichloro-1-( $\beta$-D-ribofuranosyl)- benzimidazole. J. Med. Chem. 2004, 47, 5743-5752. [CrossRef] [PubMed]

38. Bhan, P.; Bhan, A.; Hong, M.; Hartwell, J.G.; Saunders, J.M.; Hoke, G.D. 2',5'-Linked oligo-3'-deoxyribonucleoside phosphorothioate chimeras: Thermal stability and antisense inhibition of gene expression. Nucleic Acids Res. 1997, 25, 3310-3317. [CrossRef] [PubMed] 
39. Chávez-Gil, T.E.; Meléndez, E. Synthesis, spectroscopic and electrochemical characterization of water soluble $\left[\left(\eta^{5}-\mathrm{C}_{5} \mathrm{H}_{5}\right)_{2} \mathrm{Mo}\right.$ (thionucleobase/thionucleoside) $] \mathrm{Cl}_{2}$ complexes. Inorg. Chim. Acta 2004, 357, 1092-1102. [CrossRef]

40. Lin, T.-S.; Cheng, J.-C.; Ishiguro, K.; Sartorelli, A.C. Purine and 8-substituted purine arabinofuranosyl and ribofuranosyl nucleoside derivatives as potential inducers of the differentiation of the Friend erythroleukemia. J. Med. Chem. 1985, 28, 1481-1485. [CrossRef] [PubMed]

41. Lin, T.-S.; Cheng, J.-C.; Ishiguro, K.; Sartorelli, A.C. 8-Substituted guanosine and 2'-deoxyguanosine derivatives as potential inducers of the differentiation of Friend erythroleukemia cells. J. Med. Chem. 1985, 28, 1194-1198. [CrossRef] [PubMed]

42. Silverstein, R.M.; Webster, F.X.; Kiemle, D.J. Spectrometric Identification of Organic Compounds, 7th ed.; John Wiley: New York, NY, USA, 2005; pp. 92-94.

43. Vorbrüggen, H.; Krolikiewicz, K.; Bennua, B. Nucleoside syntheses, XXII Nucleoside synthesis with trimethylsilyl triflate and perchlorate as catalysts. Chem. Ber. 1981, 114, 1234-1255. [CrossRef]

44. Al Mourabit, A.; Beckmann, M.; Poupat, C.; Ahond, A.; Potier, P. New $C_{2}$ symmetrical and semisymmetrical substituted imidazolium ribonucleoside. Imidazolic nucleosides analogues. Tetrahedron Asymmetry 1996, 7 , 3455-3464. [CrossRef]

45. Lohmann, V.; Körner, F.; Koch, J.-O.; Herian, U.; Theilmann, L.; Bartenschlager, R. Replication of subgenomic hepatitis C virus RNAs in a hepatoma cell line. Science 1999, 285, 110-113. [CrossRef] [PubMed]

46. Paeshuyse, J.; Kaul, A.; de Clercq, E.; Rosenwirth, B.; Dumont, J.-M.; Scalfaro, P.; Bartenschlager, R.; Neyts, J. The non-immunosuppressive cyclosporin DEBIO-025 is a potent inhibitor of hepatitis $\mathrm{C}$ virus replication in vitro. Hepatology 2006, 43, 761-770. [CrossRef] [PubMed]

47. Kaye, P.T.; Musa, M.A. A convenient and improved Baylis-Hillman synthesis of 3-substituted 2H-1-benzopyran-2-ones. Synthesis 2002, 2701-2706. [CrossRef]

48. Gosselin, G.; Imbach, J.L.; Townsend, L.B.; Panzica, R.P. The synthesis of imidazole-2-thione nucleosides. J. Heterocycl. Chem. 1979, 16, 1185-1191. [CrossRef]

Sample Availability: Samples of all conjugated compounds are available from the authors.

(C) 2016 by the authors; licensee MDPI, Basel, Switzerland. This article is an open access article distributed under the terms and conditions of the Creative Commons by Attribution (CC-BY) license (http://creativecommons.org/licenses/by/4.0/). 